\title{
Nicotine Potentiation of Excitatory Inputs to Ventral Tegmental Area Dopamine Neurons
}

\author{
Danyan Mao, ${ }^{1}$ Keith Gallagher, ${ }^{1}$ and Daniel S. McGehee ${ }^{1,2,3}$ \\ University of Chicago ${ }^{1}$ Department of Anesthesia and Critical Care, ${ }^{2}$ Committee on Neurobiology, and ${ }^{3}$ Comprehensive Cancer Center, Chicago, Illinois \\ 60637
}

Drug-induced changes in synaptic strength are hypothesized to contribute to appetitive behavior and addiction. Nicotine, the major addictive substance in tobacco, activates nicotinic receptors (nAChRs) to initiate a series of adaptive changes at the cellular and circuit levels in brain, particularly the ventral tegmental area (VTA). Our laboratory previously reported that nicotine facilitates induction of long-term potentiation (LTP) in VTA dopamine (DA) neurons by increasing glutamate release via activation of $\alpha 7 \mathrm{nAChRs}$ on the glutamate terminals, suggesting a critical presynaptic contribution of nicotine in LTP induction. In the present study, we used an in vitro exposure paradigm to study the effect of nicotine on excitatory synaptic strength. Brief exposure of nicotine to brain slices from drugnaive adult rats followed by a period of recovery resulted in an NMDA receptor (NMDAR)-dependent increase of AMPA receptor/NMDAR ratio in VTA DA neurons, which is consistent with the induction of LTP. These effects are similar to that induced by a single in vivo nicotine injection intraperitoneally. The induction of synaptic potentiation required excitation of DA neurons mediated by somatodendritic $\alpha 4 \beta 2 \mathrm{nAChRs}$, as well as enhancement of NMDAR function via $\mathrm{D}_{5}$ dopamine receptors, also on DA neurons. Nicotine-induced increase of presynaptic glutamate release also contributed to the induction of synaptic plasticity, likely through increased activation of NMDAR. These results identified important receptor systems involved in nicotine-induced long-term changes in excitatory synaptic input to VTA DA neurons. The data also revealed remarkable similarity in the mechanisms underlying synaptic plasticity induced by nicotine and cocaine in the VTA.

\section{Introduction}

Despite effective public health campaigns that have lowered tobacco use, smoking remains a major public health problem, leading to hundreds of thousands of premature deaths each year in the United States (Centers for Disease Control and Prevention, 2004). Far beyond a simple habit, smoking is essentially a myriad of behaviors reflecting addiction to nicotine, the principal neuroactive component of tobacco. Nicotine interacts with nicotinic receptors (nAChRs) in the brain to initiate a series of adaptive changes at cellular and circuit levels. One important pathway affected by nicotine and other drugs of abuse is the dopaminergic projection from the ventral tegmental area (VTA) to the nucleus accumbens (NAc). Considerable effort is currently focused on understanding the changes in neuronal excitability that mediate the enhanced release of dopamine (DA) by drugs of abuse.

Persistent changes in synaptic activity or strength to the VTA DA neurons likely contribute to the rewarding and addictive properties of psychostimulants, including nicotine (Wolf et al., 2004; Kauer and Malenka, 2007). Acute exposure of brain slices from drug-naive young rats to nicotine can promote the induction of NMDA-dependent long-term potentiation (LTP) at ex-

Received Oct. 28, 2010; revised Jan. 17, 2011; accepted Feb. 14, 2011.

This work was supported by grants from the Women's Council of the Brain Research Foundation (to D.M.) and the National Institutes of Health (Grants DA015918, DA25875, and DA019695 to D.S.M.).

Correspondence should be addressed to Daniel S. McGehee, University of Chicago, 5841 S. Maryland Avenue, MC 4028, Chicago, IL 60637. E-mail: dmcgehee@uchicago.edu.

DOI:10.1523/JNEUROSCI.5671-10.2011

Copyright $\odot 2011$ the authors $\quad 0270-6474 / 11 / 316710-11 \$ 15.00 / 0$ citatory synapses on VTA DA neurons (Mansvelder and McGehee, 2000). In vivo administration of nicotine increases the ratio of AMPA receptor (AMPAR)/NMDA receptor (NMDAR) in DA neurons $24 \mathrm{~h}$ after exposure, consistent with the expression of LTP at these synapses (Saal et al., 2003; Gao et al., 2010). Repeated in vivo administration of cocaine results in AMPAR/ NMDAR ratio changes in VTA that are strongly correlated with locomotor sensitization (Borgland et al., 2004), suggesting that synaptic plasticity in this pathway is associated with psychostimulantinduced behavioral effects. Both NMDA receptors and $\mathrm{D}_{1}$-type dopamine receptors contribute to locomotor sensitization induced by cocaine and nicotine (Kalivas and Alesdatter, 1993; Vezina, 1996). Although numerous studies have provided important insights into the nicotine-induced changes in neuronal excitability and synaptic strength (Pidoplichko et al., 1997; Picciotto, 1998; Klink et al., 2001; Placzek et al., 2009; Gao et al., 2010), the location and functional contribution of specific receptor subtypes to the induction of synaptic plasticity by nicotine within the adult VTA has not been systematically investigated.

Recently, Argilli and colleagues (2008) showed that exposure of brain slices from naive rats to cocaine followed by $3-5 \mathrm{~h}$ of recovery without the drug induced synaptic plasticity similar to that observed after in vivo exposure. Following up on earlier in vivo observations, they demonstrated that this effect of cocaine was dependent upon $\mathrm{D}_{1} / \mathrm{D}_{5}$ DA receptors and NMDARs. However, the potential contribution of these receptor systems to the persistent effects of nicotine on VTA DA neurons is unknown. Here, we established a similar paradigm to systematically in- 
A

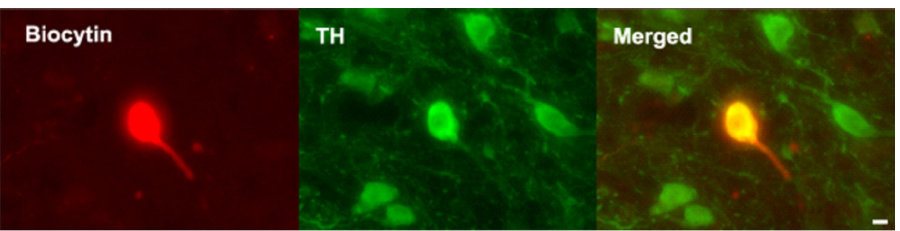

B
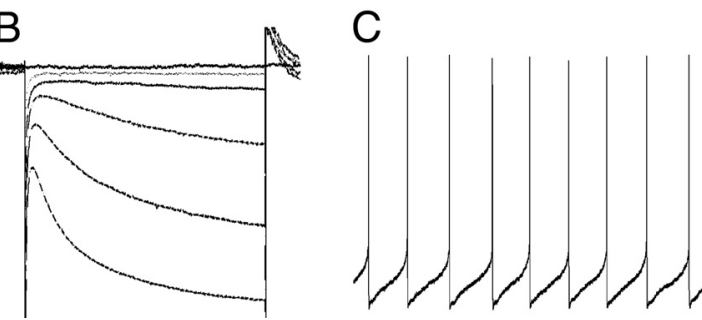

D

Figure 1. Dopamine neuron identification in the VTA. $\boldsymbol{A}$, Immunohistochemistry of a VTA neuron filled with biocytin via the recording electrode. Left, Biocytin staining; middle, TH staining; right, colabeling of biocytin and TH ( $n=17)$. $\boldsymbol{B}$, A representative trace of $\mathrm{I}_{\mathrm{h}}$ induced by hyperpolarizing steps from -40 to $-55 \mathrm{mV}$ through $-115 \mathrm{mV}$ in $10 \mathrm{mV}$ increments. One criterion for DA neuron identification was $\mathrm{I}_{\mathrm{h}}>200 \mathrm{pA}$ at $-115 \mathrm{mV}$. C, Representative whole-cell recording of regular spontaneous action potentials. Another criterion for DA neuron identification was a spontaneous firing rate between 0 and $5 \mathrm{~Hz}$. D, Representative trace of an action potential from a DA neuron. DA neurons were associated with action potential duration of $>2 \mathrm{~ms}$. Scale bar: $\boldsymbol{A}, 10 \mu \mathrm{m}$. Calibration: $\boldsymbol{B}, 80 \mathrm{~ms}, 80 \mathrm{pA} ; \boldsymbol{C}, 350 \mathrm{~ms}, 6.25 \mathrm{mV} ; \boldsymbol{D}, 1.0 \mathrm{~ms}, 10 \mathrm{mV}$.

vestigate the receptor systems that contribute to the nicotineinduced changes in excitatory synaptic input to VTA DA neurons.

\section{Materials and Methods}

Slice preparation. Adult postnatal day 60-90 (P60-P90) male Sprague Dawley rats (Harlan Laboratory) were used for all experiments. Rats were rapidly decapitated following anesthesia with isoflurane (Abbott Laboratories). Their brains were removed into the cold sucrose-artificial CSF (aCSF) (in mu: sucrose 125, $\mathrm{KCl} 2.5, \mathrm{Mgcl}_{2} 1, \mathrm{CaCl}_{2} 2.5$, glucose 20, $\mathrm{NaH}_{2} \mathrm{PO}_{4} 1, \mathrm{NaHCO}_{3} 25$, ascorbic acid 10; bubbled continuously with $95 \% \mathrm{O}_{2} / 5 \% \mathrm{CO}_{2}$ ), and $200-\mu \mathrm{m}$-thick horizontal slices containing VTA were cut with a vibratome (VT100S, Leica). Slices were incubated in a holding chamber of circulating $32^{\circ} \mathrm{C}$ aCSF (in $\mathrm{mm}, 125 \mathrm{NaCl}, 25$ $\mathrm{NaHCO}_{3}, 20$ glucose, $2.5 \mathrm{KCl}, 2.5 \mathrm{CaCl}_{2}, 1 \mathrm{MgCl}_{2}, 1 \mathrm{NaH}_{2} \mathrm{PO}_{4}$, and 1 ascorbic acid, $\mathrm{pH} 7.4$, saturated with $95 \% \mathrm{O}_{2}$ and $5 \% \mathrm{CO}_{2}$ ) and perfused at a rate of $20 \mathrm{ml} / \mathrm{min}$ for at least $30 \mathrm{~min}$ before drug exposure or recording. For recordings, an individual slice was transferred to a recording chamber superfused $(\sim 2 \mathrm{ml} / \mathrm{min})$ with $32^{\circ} \mathrm{C}$ aCSF without ascorbic acid. For recordings of AMPAR/NMDAR ratio, paired-pulse ratio, spontaneous EPSC (sEPSC), and NMDA EPSCs, bicuculline $(20 \mu \mathrm{M})$ was included in an external solution to block $\mathrm{GABA}_{\mathrm{A}}$ receptor-mediated synaptic currents. Bicuculline has been shown to inhibit recombinant nAChRs expressed in Xenopus oocytes (Demuro et al., 2001). Although we did not systematically examine the extent of interaction of bicuculline with nAChRs in our recordings, both direct and indirect nicotinic responses were clearly resolvable in those experiments that required the presence of bicuculline.

Cell identification. Neurons were visualized under infrared illumination using an upright microscope (Axioskop, Zeiss). In whole-cell recordings, VTA DA neurons were identified by the following criteria: prominent hyperpolarization activated current $\left(\mathrm{I}_{\mathrm{h}}\right)(>200 \mathrm{pA}$ at -115 $\mathrm{mV})$, slow pacemaker-like firing rate $(<5 \mathrm{~Hz})$, long action potential duration $(>2 \mathrm{~ms}$ ), cell morphology, and anatomical location (Johnson and North, 1992). In on-cell recordings, we identified DA neurons using all these criteria except $\mathrm{I}_{\mathrm{h}}$. Intracellular cesium alters firing rate and action potential shape, and suppresses $\mathrm{I}_{\mathrm{h}}$. Therefore, in the whole-cell recordings that required a cesium internal solution, we determined the firing rate of neurons by doing a brief period of on-cell recording. When $\mathrm{I}_{\mathrm{h}}$ was tested early in the recording, some cells did display significant currents, but these were quickly suppressed by cesium. In separate whole-cell recordings with potassium internal solutions, all of the neu-

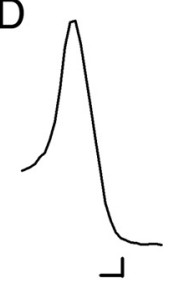

rons identified as dopaminergic by anatomical location, cell morphology, and firing rate also expressed an $\mathrm{I}_{\mathrm{h}}>200 \mathrm{pA}$ at $-115 \mathrm{mV}$.

Recent findings have suggested that non-DA neurons in the VTA may also express $\mathrm{I}_{\mathrm{h}}$, and the conventional criteria mentioned above may not reliably predict cell identity in the VTA (Ford et al., 2006; Margolis et al., 2006). However, recording time may confound immunocytochemical detection of tyrosine hydroxylase (TH), as prolonged recording in DA neurons appears to either dilute $\mathrm{TH}$ concentration to below the detection threshold or alter the molecular interactions between the antibodies and the enzyme (Zhang et al., 2010). Therefore, in a subset of the experiments, we included biocytin in our internal solution and performed immunohistochemistry of TH and biocytin after brief recordings of between 5 and $10 \mathrm{~min}$. With this protocol, 16 of 17 cells displayed colabeling of TH and biocytin clearly above background fluorescence levels determined by Image), indicating that virtually all of the cells identified with our electrophysiological and anatomical criteria were indeed DA neurons (see Fig. 1).

Electrophysiology. Recordings were obtained with electrodes $(2-5 \mathrm{M} \Omega$ ) made from borosilicate glass. In whole-cell recordings of AMPAR/NMDAR ratio and NMDA EPSC experiments, electrodes were filled with an internal solution containing the following (in $\mathrm{mM}$ ): 117 cesium gluconate, 20 HEPES, 0.4 EGTA, $2.8 \mathrm{NaCl}, \quad 2.5$ ATP, 0.25 GTP, 5 tetraethylammonium- $\mathrm{Cl}$, and 20 glucose, with $\mathrm{pH}$ adjusted to 7.4 (280$290 \mathrm{mOsm}$ ). In whole-cell recordings of paired-pulse ratio and sEPSCs, the internal solution contained the following (in mM): $154 \mathrm{~K}$-gluconate, $1 \mathrm{KCL}, 1$ EGTA, 10 HEPES, 10 glucose, 5 ATP, and $0.1 \mathrm{GTP}$, with pH adjusted to 7.4 with $\mathrm{KOH}$ (320 mOsm). In on-cell recordings, electrodes were filled with the aCSF described above. For evoked EPSCs, a tungsten bipolar stimulating electrode (FHC) was placed at a distance of 100-200 $\mu \mathrm{m}$ rostral to the recording electrode, and afferents were stimulated at $0.1 \mathrm{~Hz}$. All currents were recorded using an Axopatch 200B amplifier with a DigiData 1322A interface and Clampex 8.2 software (Molecular Devices), filtered at $2 \mathrm{kHz}$ and digitized at $10 \mathrm{kHz}$. Series resistance in whole-cell recordings was $<20 \mathrm{M} \Omega$ and was monitored throughout the recordings. Cells with changes in series resistance of $>10 \%$ were not included in the analysis.

In experiments involving in vitro drug exposure, slices were prepared as described. After 30 min recovery in aCSF, individual slices were transferred to the recording chamber and perfused with test drugs for 15-20 min, as indicated in Figure $2 \mathrm{~A}$. After drug exposure, slices were perfused with regular aCSF for $10 \mathrm{~min}$ in the same chamber before removal to initial recovery chamber for 150-300 min.

Two different methods were used to determine the AMPAR/NMDAR ratio of the glutamatergic inputs to VTA DA neurons. First, neurons were voltage-clamped at $-70 \mathrm{mV}$, where the evoked EPSC was mostly AMPA receptor-mediated current that decayed to baseline within $40 \mathrm{~ms}$ after the peak. Then the neuron was depolarized to $+40 \mathrm{mV}$ to remove $\mathrm{Mg}^{2+}$ block of NMDA receptors, and EPSCs contained both AMPAR- and NMDARmediated currents. The AMPA EPSC was measured at the time corresponding to the peak at $-70 \mathrm{mV}$, while the NMDA EPSC was measured during a $10 \mathrm{~ms}$ window starting $40 \mathrm{~ms}$ after the AMPAR EPSC peak. In the second method, VTA DA neurons were voltage-clamped at $+40 \mathrm{mV}$ throughout recording. AMPA EPSC was isolated from mixed-component EPSC by blocking NMDA receptors with D-2-amino-5-phosphonovalerate (AP5; 50 $\mu \mathrm{M})$. NMDA EPSC was determined by subtraction of the AMPA current from mixed-component EPSC. In both cases, the AMPAR/NMDAR ratio was obtained by dividing the AMPA EPSC by the NMDA EPSC. In all recordings, 10 sweeps were averaged to construct each EPSC trace.

For paired-pulse ratio measurements, two stimuli were applied at an interval of $50 \mathrm{~ms}$, and 10 sweeps were averaged to obtain one paired- 

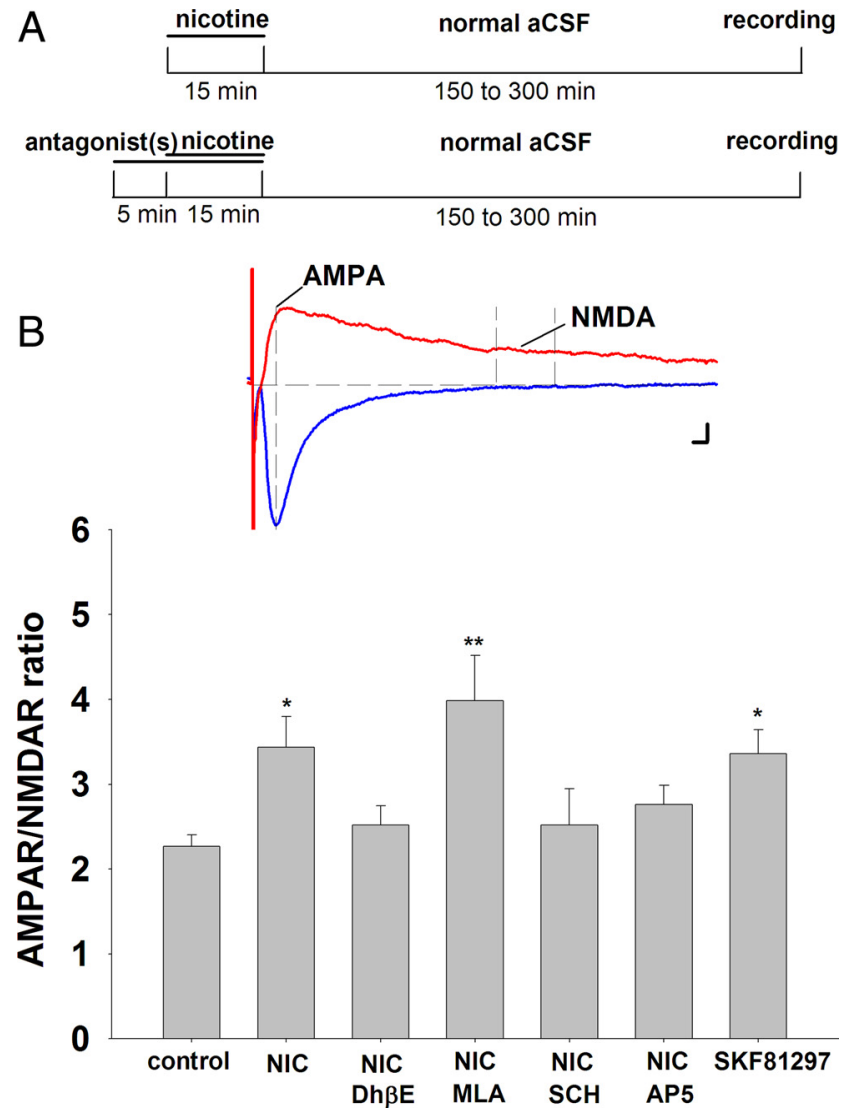

Figure 2. In vitro nicotine or $D_{1} / D_{5}$ dopamine receptor activation increases $A M P A R / N M D A R$ ratio in VTA DA neurons. $A$, Schemata for in vitro nicotine exposure. Top, Horizontal brain slices from drug-naive rats were exposed to nicotine $(1 \mu \mathrm{m})$ or vehicle for $15 \mathrm{~min}$ before incubation in drug-free normal aCSF $\left(32^{\circ} \mathrm{C}\right)$. After $150-300 \mathrm{~min}$, slices were transferred to a recording chamber for electrophysiology. Bottom, Slices were pretreated with antagonists to various neurotransmitter receptors for $5 \mathrm{~min}$ before and throughout the nicotine exposure. $\boldsymbol{B}$, Summary of nicotinic and $D_{1} / D_{5}$ receptor effects on AMPAR/NMDAR ratio. Inset, Representative traces of AMPAR- and NMDAR-mediated EPSC. AMPA EPSC was measured with $\mathrm{Vm}=+40 \mathrm{mV}$ at the time corresponding to the peak of the EPSC elicited with $\mathrm{Vm}=-70 \mathrm{mV}$; NMDA EPSC was measured with $\mathrm{Vm}=+40 \mathrm{mV}$ during a $10 \mathrm{~ms}$ window $40 \mathrm{~ms}$ after the peak of AMPA EPSC, when the latter decayed to baseline. Nicotine $(1 \mu \mathrm{m} ; n=7)$ and SKF $81297(10 \mu \mathrm{m} ; n=10)$ increased AMPAR/NMDAR ratio in DA neurons compared with vehicle control $(n=11)$. The nicotine-induced increase was inhibited by $\operatorname{Dh} \beta \mathrm{E}(1 \mu \mathrm{m} ; n=5), \mathrm{SCH} 23390(10 \mu \mathrm{m} ; n=7)$, and $\operatorname{AP5}(50 \mu \mathrm{m} ; n=9)$, but not MLA $(10 \mathrm{~nm} ; n=6)$. ANOVA: $p=0.0032 ;$ Bonferroni post hoc test: ${ }^{*} p<0.05,{ }^{* *} p<0.01$. Calibration: $\boldsymbol{B}, 5 \mathrm{~ms}, 25 \mathrm{pA}$.

pulse EPSC trace. The paired-pulse ratio was calculated by dividing the amplitude of the EPSC evoked by the second stimulus by the amplitude of the EPSC evoked by the first stimulus (P2/P1).

Action potentials were monitored in current-clamp mode in either on-cell or whole-cell recording configuration, as indicated in Results. Action potential frequency and sEPSC were analyzed off-line with MiniAnalysis software (Synaptosoft). Detection threshold for sEPSC was set at $15 \mathrm{pA}$, which is at least four times the root mean square of the baseline noise. After the software selected individual events, each detected event was visually inspected to eliminate artifacts. The averaged sEPSC or action potential frequency within the $1 \mathrm{~min}$ immediately before drug administration was taken as baseline, and the averaged frequency for the $1 \mathrm{~min}$ period centered on the peak response was taken for drug effect.

Data analysis. ANOVA was used to determine the main effects of treatments in AMPAR/NMDAR ratio and NMDA EPSC experiments. Bonferroni post hoc analysis was used to assess effects between treatment groups. Student's $t$ test was used in experiments of firing rate and sEPSC to assess the drug effect on each cell. A paired $t$ test was used in the summarized data of paired-pulse ratio, firing rate, and sEPSC for group comparison between baseline and treatment. Statistical signif-
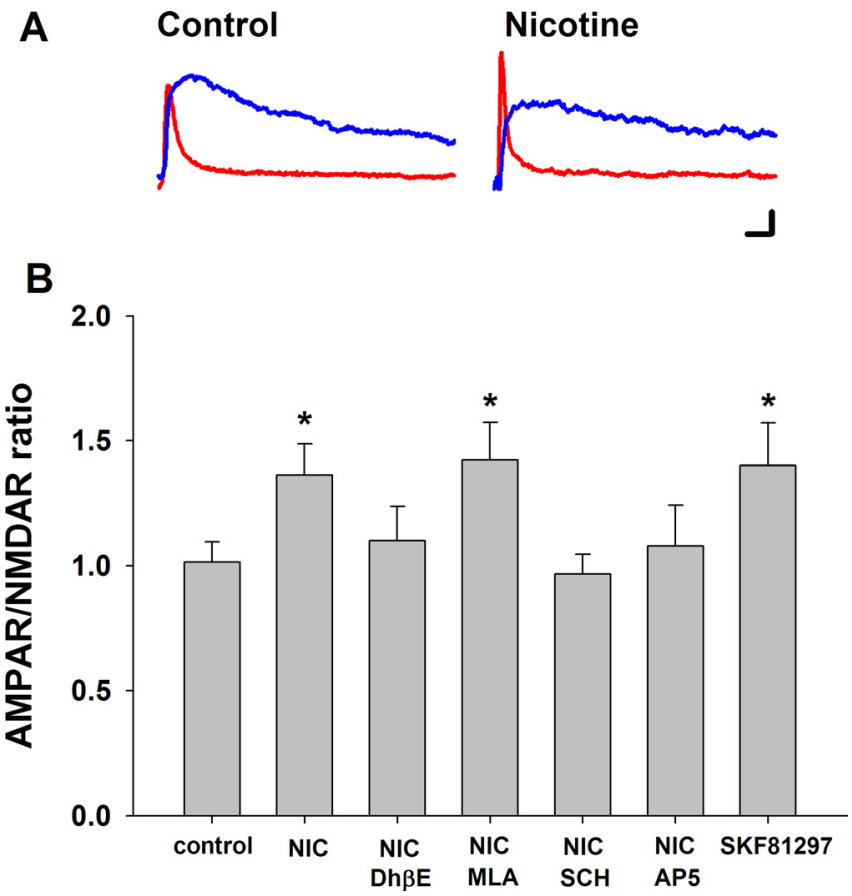

Figure 3. In vitro nicotine or $D_{1} / D_{5}$ dopamine receptor agonist increases AMPAR/NMDAR ratio in VTA DA neurons. Timing of the drug pretreatments and assessment of synaptic transmission was identical to that illustrated in Figure 2. For these AMPAR/NMDAR determinations, VTA DA neurons were voltage-clamped at $+40 \mathrm{mV}$ throughout recording. AMPA EPSC was isolated from mixed-component EPSC by blocking NMDA receptors with $50 \mu \mathrm{M}$ AP5. NMDA EPSC was determined by subtraction of the AMPA current from mixed-component EPSC. $\boldsymbol{A}$, Representative traces of AMPAR-mediated (red) and NMDAR-mediated (blue) EPSC under control condition and after nicotine exposure. $\boldsymbol{B}$, Summary of receptor agonist and antagonist effects on AMPA/NMDAR ratio. Both $1 \mu \mathrm{m}$ nicotine and $10 \mu \mathrm{m}$ SKF 81297 significantly increased AMPAR/NMDAR ratio in VTA DA neurons after the in vitro exposure paradigm. The antagonists $1 \mu \mathrm{M} \mathrm{Dh} \beta \mathrm{E}, 10 \mu \mathrm{M} \mathrm{SCH} 23390$, or $50 \mu \mathrm{M}$ AP5 each inhibited nicotine-induced increase of AMPAR/NMDAR ratio, but not MLA (10 nM); $n=13$ for control; $n=7$ for nicotine; $n=8$ for $\mathrm{MLA}, \mathrm{DH} \beta \mathrm{E}$, and SCH23390; $n=5$ for AP5; and $n=7$ for SKF 81297. ANOVA, $p<0.05$; Bonferroni post hoc, ${ }^{*} p<0.05$. Calibration: $\boldsymbol{A}, 10 \mathrm{~ms}, 20 \mathrm{pA}$.

icance was determined by $p<0.05$. All statistical tests were performed using GraphPad software (Prism). All results were presented as means \pm SEM.

Immunohistochemistry. Brain slices were fixed in PBS containing 4\% paraformaldehyde for $2 \mathrm{~h}$, placed in PBS containing 30\% sucrose overnight at $4^{\circ} \mathrm{C}$, and then resectioned to $35-\mu \mathrm{m}$-thick sections with a cryostat (CM3050 S, Leica). The sections were washed twice for $5 \mathrm{~min}$ with PBS, blocked, and permeabilized with PBS containing 3\% normal goat serum (NGS) and $0.5 \%$ Triton X-100 (NGS/Triton X-PBS) for $2 \mathrm{~h}$, and then washed twice for $5 \mathrm{~min}$ with PBS at room temperature (RT). For immunostaining of TH and biocytin, sections were incubated with the primary antibody (rabbit anti-TH, Millipore) at a 1:500 dilution in NGS/Triton X-PBS for $24 \mathrm{~h}$ at $4^{\circ} \mathrm{C}$. After being washed three times for 5 min with PBS, sections were incubated with secondary antibodies (Alexa Fluor 488 goat anti-rabbit, streptavidinAlexa Fluor 594 conjugate, Invitrogen) at a 1:200 dilution in PBS containing $0.1 \%$ Triton X-100 for $1 \mathrm{~h}$ at RT. For sequential immunostaining of $\mathrm{TH}$ and $\mathrm{D}_{5}$ receptors, similar incubation and washing steps were performed for second primary antibody (i.e., sections were washed $3 \times 5 \mathrm{~min}$ in PBS, blocked in NGS/Triton X-PBS for $30 \mathrm{~min}$, and then washed $2 \times 5 \mathrm{~min}$ in PBS at RT before incubation with second primary antibody, mouse anti-D5R, Abcam) diluted at 1:1000 in Triton X-PBS for $24 \mathrm{~h}$ at $4^{\circ} \mathrm{C}$. They were then washed three times with PBS. Sections were then incubated with the secondary antibodies (Alexa Fluor 488 goat anti-mouse and Alexa Fluor 594 goat antirabbit) at a 1:200 dilution in PBS containing $0.1 \%$ Triton X-100 for $2 \mathrm{~h}$ at RT. Finally, the sections were washed three times for $5 \mathrm{~min}$ with 
A

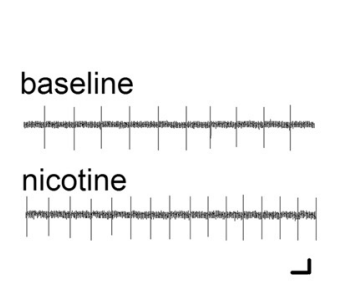

B
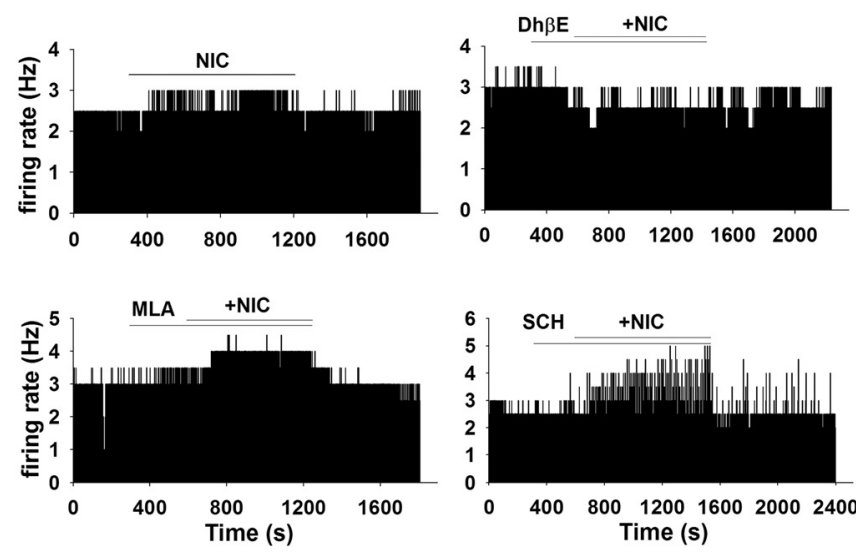

$\mathrm{C}$

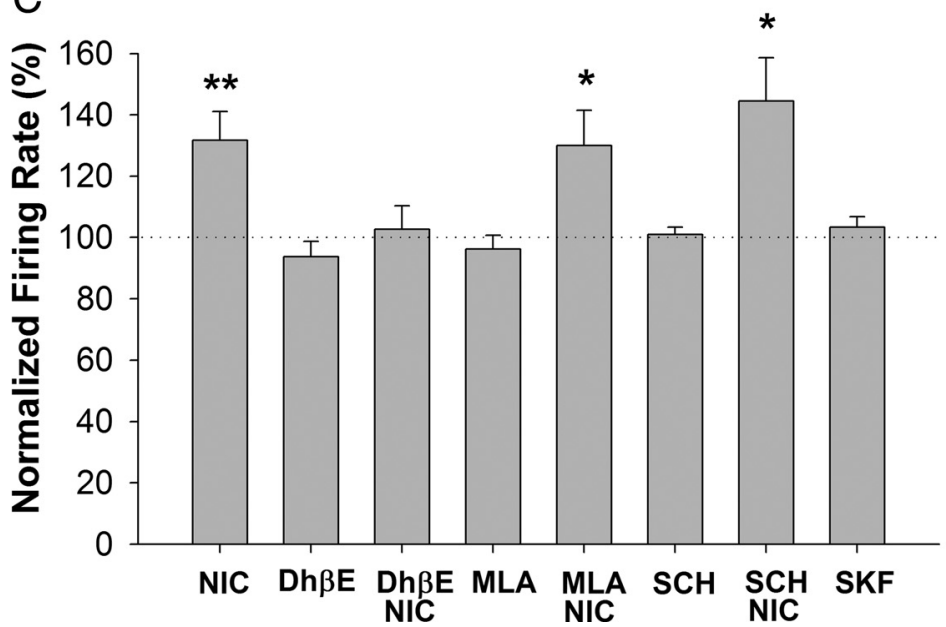

baseline
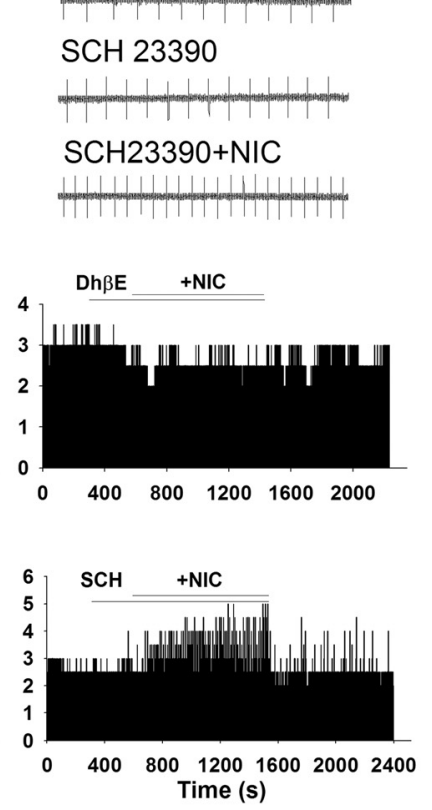

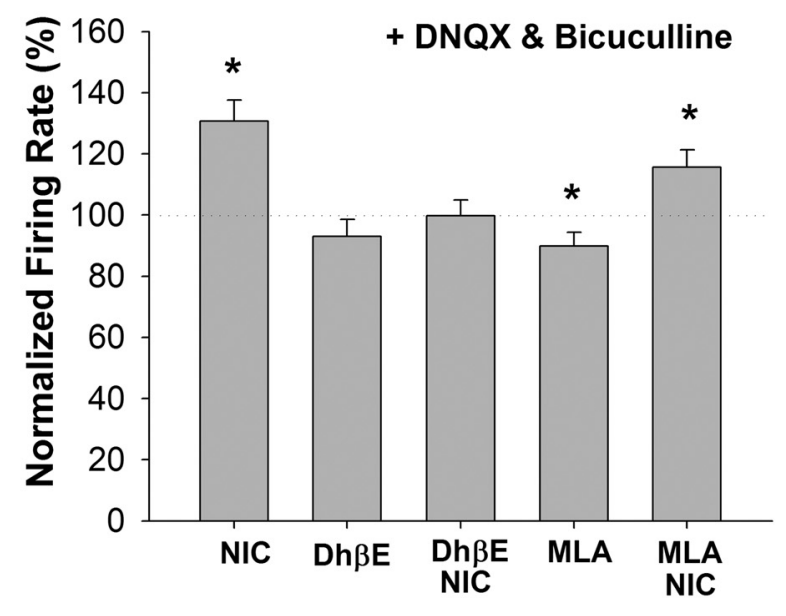

Figure 4. VTA DA neuron firing rate effects of nicotine and a $D_{1} / D_{5}$ agonist in the presence and absence of various receptor antagonists. $A$, Representative traces of on-cell recordings of spontaneous firing from example neurons in response to nicotine (1 $\mu \mathrm{m}$; left), SCH $23390(10 \mu \mathrm{M})$, and SCH $23390+$ nicotine (right). $\boldsymbol{B}$, Representative histograms of firing rate in response to nicotine in the presence of antagonists to nAChRs (10 nM MLA and $1 \mu \mathrm{M} \mathrm{Dh} \beta \mathrm{E}$ ) and $\mathrm{D}_{1} / \mathrm{D}_{5}$ receptors (10 $\left.\mu \mathrm{mSCH} 23390\right)$. C, Summary of VTA DA neuron firing rate results. Nicotine (1 $\left.\mu \mathrm{m} ; n=19\right)$ increased the firing rate of DA neurons, whereas the $D_{1} / D_{5}$ agonist SKF $81297(10 \mu \mathrm{m} ; n=9)$ had no effect. Nicotine-induced increase in firing rate was inhibited by Dh $\beta E(1 \mu \mathrm{m} ; n=5)$, but not MLA $(10 \mathrm{~nm} ; n=9)$ or SCH $23390(10 \mu \mathrm{m} ; n=10)$. MLA, Dh $\beta E$, and SCH 23390 alone had no effect on the firing rate of VTA DA neurons. All data are normalized to baseline firing rate before drug application. ${ }^{*} p<0.05,{ }^{* *} p<0.01$. Calibration: $500 \mathrm{~ms}, 4 \mathrm{mV}$. D, Fast synaptic transmission was inhibited by pretreatment with DNQX (10 $\left.\mu \mathrm{m}\right)$ and bicuculline (20 $\left.\mu \mathrm{m}\right)$. Left, Representative traces of on-cell recordings of spontaneous firing from example neurons in response to drugs. Right, Representative firing rate histograms from example neurons in response to each drug combination. $E$, Summary of firing rate data in the presence of DNQX $(1 \mu \mathrm{M})$ and bicuculline $(20 \mu \mathrm{M})$. Nicotine $(1 \mu \mathrm{M})$ increased the firing rate of $\mathrm{DA}$ neurons under these conditions $(n=22)$. Dh $\beta E(1 \mu \mathrm{m} ; n=5)$, but not MLA $(10 \mathrm{~nm} ; n=9)$ blocked the nicotine-induced increase of firing rate in DA neurons. MLA treatment alone significantly decreased the baseline firing rate of DA neurons. ${ }^{*} p<0.05$. Calibration: $\boldsymbol{A}, 500 \mathrm{~ms}, 5 \mathrm{mV} ; \boldsymbol{B}, 500 \mathrm{~ms}, 3 \mathrm{mV} ; \boldsymbol{C}, 500 \mathrm{~ms}, 2 \mathrm{mV}$.

PBS, mounted with anti-fade mounting medium containing $n$-propyl gallate, and coverslipped.

\section{Results}

Our recordings were performed in horizontal brain slices from adult male rats that include the VTA. DA neurons were identified by several criteria. Anatomical location and large soma diameter were used in combination with electrophysiological features including regular, low-frequency firing in the absence of stimulation $(<5 \mathrm{~Hz})$, action potential duration $>2 \mathrm{~ms}$, and $\mathrm{I}_{\mathrm{h}}$ currents $>200$ pA when the voltage was stepped from -40 to $-115 \mathrm{mV}$ (Johnson and North, 1992; Zhang et al., 2010), as shown in Figure 1. A recent study showed that lateral VTA DA neurons display a substantially larger $\mathrm{I}_{\mathrm{h}}$ than medial VTA neurons with mean peak amplitude $>300 \mathrm{pA}$ and $88 \%$ of the lateral neurons display $\mathrm{I}_{\mathrm{h}}>100 \mathrm{pA}$ (Zhang et al., 2010). Given that our recordings were mostly contained in the lateral VTA, near the medial border of the medial terminal nucleus, and that we used a threshold for $\mathrm{I}_{\mathrm{h}}$ of $200 \mathrm{pA}$, we contend that our recordings were predominantly from DA neurons. Postrecording immunohistochemistry revealed a strong correlation between these criteria and tyrosine hydroxylase expression in a subset of the recorded cells (Fig. 1A). 


\section{Nicotine-induced changes in excitatory synaptic strength in VTA}

To assess the influence of nicotine on the strength of excitatory synaptic inputs to VTA DA neurons, we used an in vitro drug exposure paradigm (Fig. 2A) similar to that reported previously for cocaine (Argilli et al., 2008). Horizontal brain slices from drug-naive adult rats were exposed to $1 \mu \mathrm{M}$ nicotine for $15 \mathrm{~min}$, and then removed and placed in normal drug-free aCSF for recovery for 150-300 min before recording. Antagonists to individual neurotransmitter receptors preceded nicotine by $5 \mathrm{~min}$ and were continuously present during nicotine exposure.

AMPAR/NMDAR ratio was determined by initially voltageclamping the VTA DA neuron at $-70 \mathrm{mV}$ to evoke EPSCs that are mediated almost exclusively by AMPA receptors, which decayed to baseline within $40 \mathrm{~ms}$ after the peak. Then the neuron was depolarized to $+40 \mathrm{mV}$ to remove $\mathrm{Mg}^{2+}$ block of NMDA receptors. The AMPA EPSC was measured at the time corresponding to the peak at $-70 \mathrm{mV}$, and the NMDA EPSC was measured as the average of the current during a $10 \mathrm{~ms}$ window 40 ms after the peak AMPA current. These values were used to calculate the AMPAR/NMDAR ratio (Fig. 2 B). A $1 \mu \mathrm{M}$ nicotine exposure followed by an extended recovery period induced an increase of AMPAR/NMDAR ratio in the VTA DA neurons to $148 \%$ of control (control $=2.3 \pm 0.1, n=11$; nicotine $=3.4 \pm$ $0.4, n=7$; ANOVA, $p=0.0032$; post hoc test, $p<0.05$ ), which is consistent with the induction of LTP at these synapses (Fig. 2C) (Ungless et al., 2001). Pretreating the slices with $1 \mu \mathrm{M} \mathrm{Dh} \beta \mathrm{E}$, a selective $\beta 2 \mathrm{nAChR}$ antagonist, completely blocked the nicotine effect on synaptic potentiation, suggesting a critical role of $\beta 2$ $n A C h R s$ in the induction of synaptic potentiation in VTA (nicotine $+\mathrm{Dh} \beta \mathrm{E}=2.5 \pm 0.2, n=5 ; p>0.05)$. Pretreatment with the selective $\alpha 7 \mathrm{nAChR}$ antagonist, methyllycaconitine citrate (MLA, $10 \mathrm{nM}$ ) had no effect on the nicotine-induced increase in the AMPAR/NMDAR ratio under these conditions (nicotine + $\mathrm{MLA}=4.0 \pm 0.6, n=6 ; p<0.01)$. In addition, pretreatment with either the $D_{1} / D_{5}$ receptor antagonist, SCH23390 $(10 \mu \mathrm{M})$, or NMDA receptor antagonist AP5 $(50 \mu \mathrm{M})$ blocked the nicotineinduced increase of AMPAR/NMDAR ratio (nicotine $+\mathrm{SCH} 23390=2.5 \pm 0.5, n=7 ; p>0.05$; nicotine + AP5 $=$ $2.8 \pm 0.2, n=9 ; p>0.05)$. We also tested whether synaptic plasticity could be induced by a nicotine concentration similar to that recently measured in the brains of human subjects after smoking a cigarette (Rose et al., 2010). In slices exposed to $300 \mathrm{~nm}$ nicotine, we observed an increase of AMPAR/NMAR ratio in DA neurons similar to that seen with $1 \mu \mathrm{M}$ nicotine $($ control $=2.51 \pm$ $0.6, n=6 ; 300$ nM nicotine $=4.16 \pm 0.43, n=7 ; p<0.05)$. We also found that treatment of the slices with the $D_{1} / D_{5}$ receptor agonist SKF $81297(10 \mu \mathrm{M})$ alone was sufficient to increase AMPAR/NMDAR ratio to $148 \%$ of control in this exposure para$\operatorname{digm}($ SKF $81297=3.4 \pm 0.3, n=10 ; p<0.05)$ (Fig. $2 B)$.

In a separate set of experiments, we used the same method for measuring AMPAR/NMDAR ratio as that reported by Argilli et al. (2008). VTA DA neurons were voltage-clamped at $+40 \mathrm{mV}$ throughout recording. AMPA EPSC was isolated from mixedcomponent EPSC by blocking NMDA receptors with AP5 (50 $\mu \mathrm{M})$. This method revealed an identical pharmacological profile to that outlined above, supporting the validity of our AMPAR/ NMDAR ratio determinations (Fig. 3). Our findings are consistent with the reported synaptic changes associated with cocaine exposure (Ungless et al., 2001; Argilli et al., 2008), suggesting mechanistic overlap in the enhancement of VTA synaptic strength by nicotine and cocaine.
A baseline

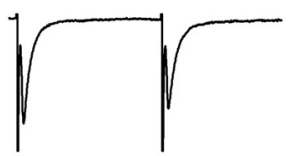

baseline

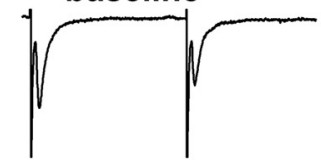

B

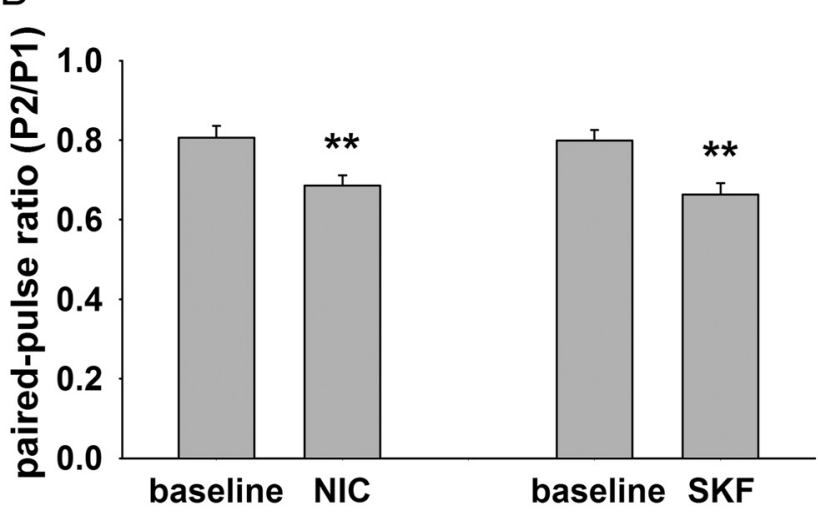

C
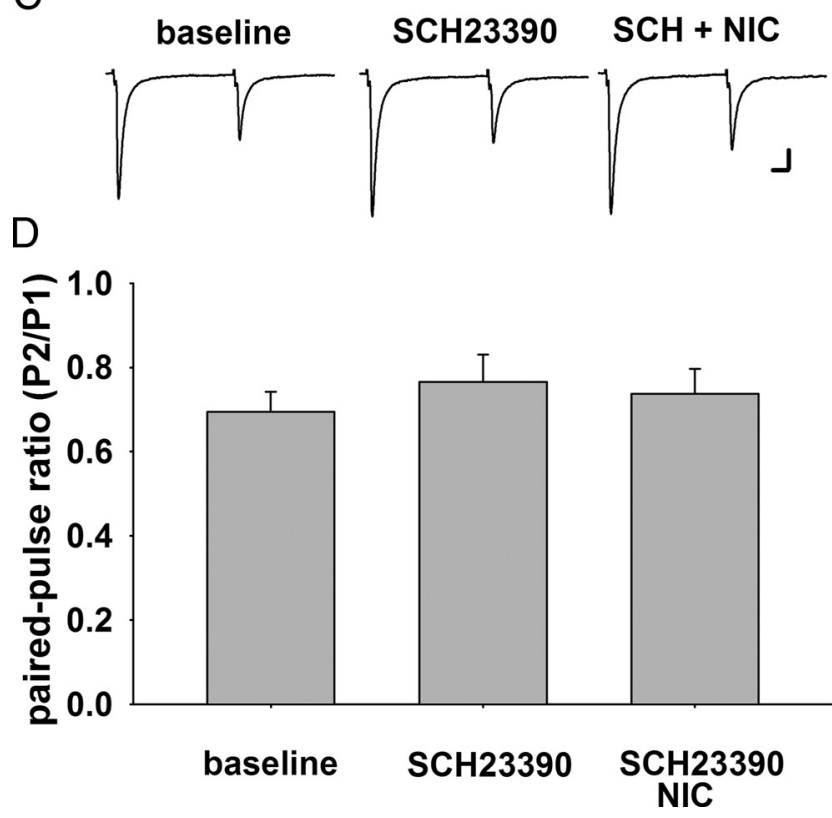

Figure 5. Activation of nicotinic or $D_{1} / D_{5}$ receptors decreases paired-pulse ratio of excitatory inputs to VTA DA neurons. A, Representative traces of paired EPSCs elicited by two stimuli with a $50 \mathrm{~ms}$ interval in two different DA neurons voltage-clamped at $-70 \mathrm{mV}$. $\boldsymbol{B}$, Summary of paired-pulse ratio under baseline conditions and in the presence of nicotine $(1 \mu \mathrm{m} ; n=11)$ and SKF $81297(10 \mu \mathrm{m} ; n=$ 18). Both drugs decreased the paired-pulse ratio in DA neurons. $C$, Representative traces of paired EPSCs under baseline, $S \mathrm{CH} 23390(10 \mu \mathrm{M})$, and SCH 23390 + nicotine treatment. D, Summary of the paired-pulse ratio under baseline conditions and in the presence of $\mathrm{SCH} 23390(10 \mu \mathrm{m} ; n=12)$ alone or SCH23390 + nicotine. SCH 23390 had no effect alone, but it inhibited the effect of nicotine on paired-pulse ratio, indicating that $D_{1} / D_{5}$ activity is necessary for nicotinic modulation of the probability of glutamate release at the inputs to VTA DA neurons. ${ }^{* *} p<0.01$. Calibration: $A$, top, $5 \mathrm{~ms}, 30 \mathrm{pA} ; A$, bottom, $20 \mathrm{pA} ; \mathrm{C}, 4 \mathrm{~ms}, 40 \mathrm{pA}$.

Receptors and transmitters that mediate the induction of synaptic plasticity by nicotine

To further delineate the mechanisms underlying nicotineinduced synaptic potentiation in VTA, we focused on the induc- 
A

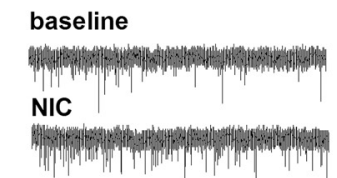

$\operatorname{Dh} \beta E$
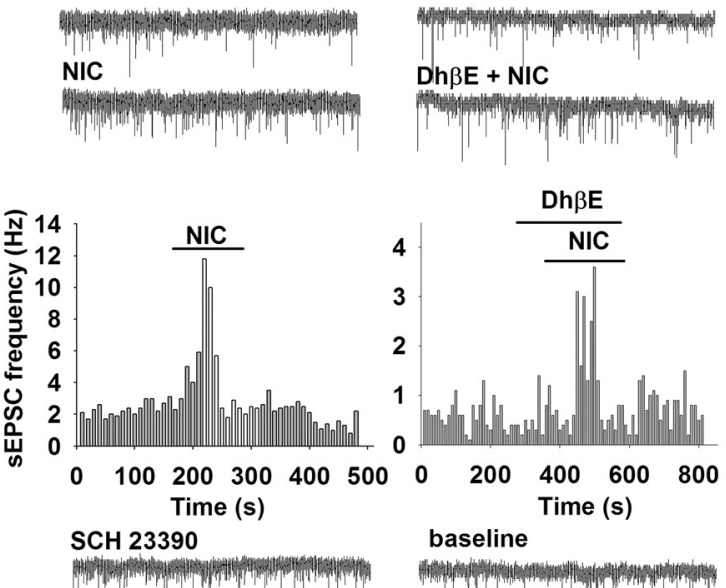

SCH $23390+$ NIC

Hath
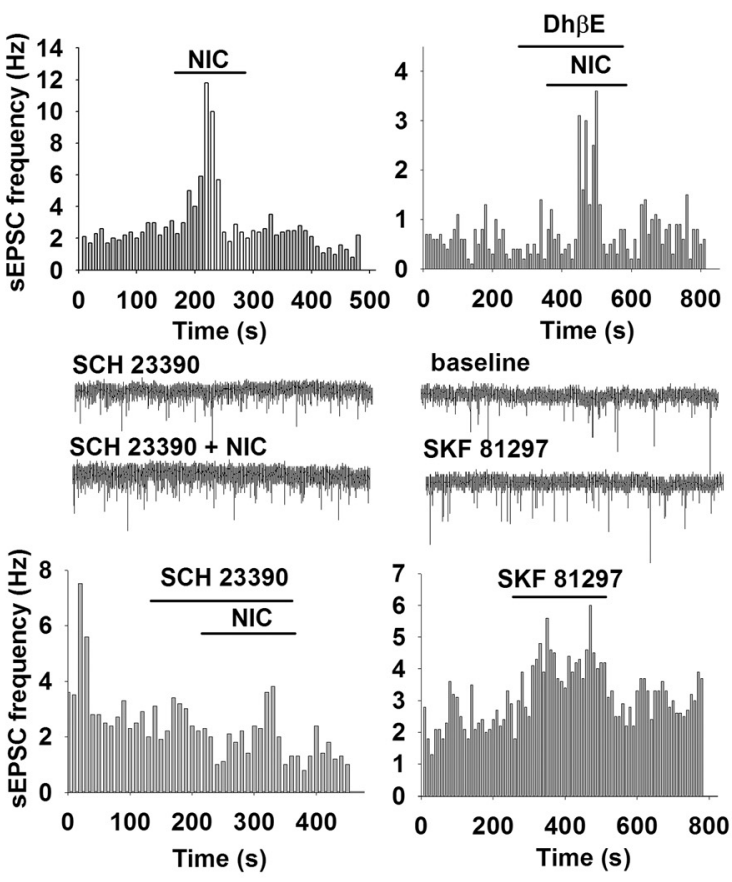

baseline
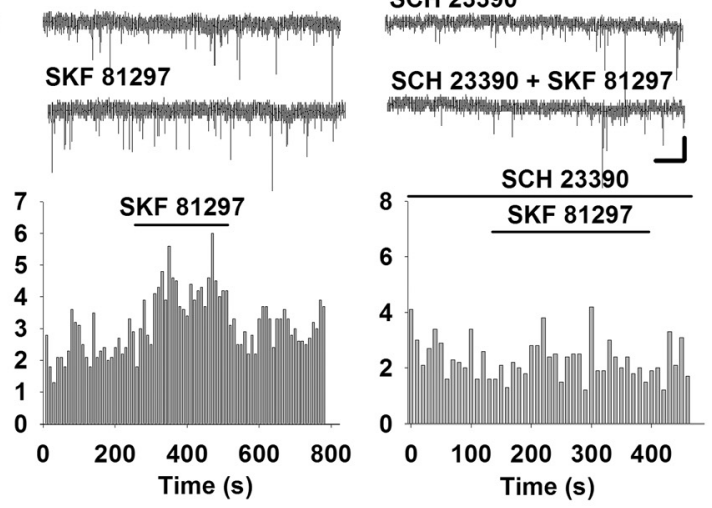
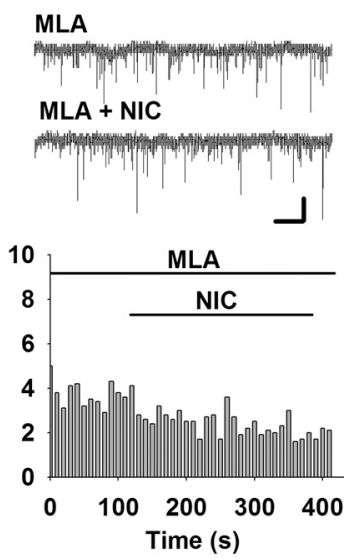

SCH 23390
B

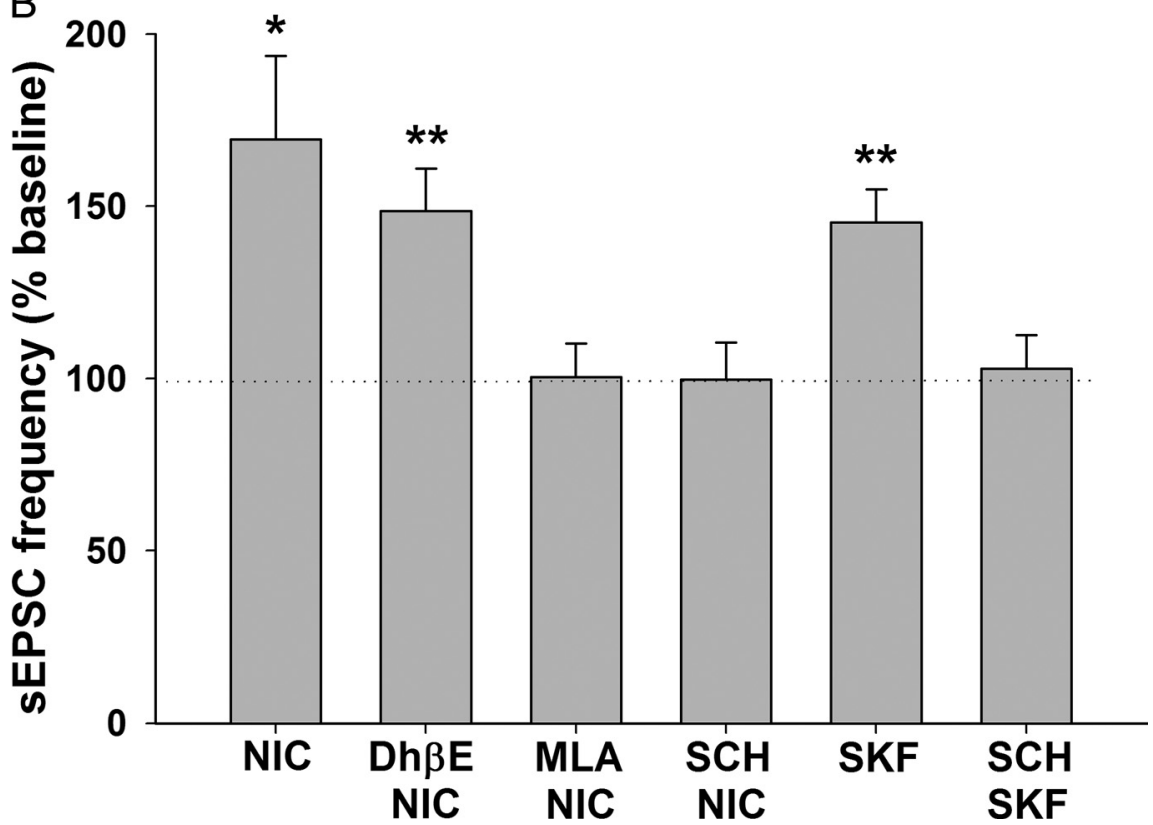

Figure 6. Activation of nicotinic or $D_{1} / D_{5}$ receptors enhances glutamatergic synaptic inputs to VTA DA neurons. $A$, Representative traces of sEPSCs and histograms of $s$ EPSC frequency in response to various drugs. $B$, Summary of the effect of various nicotinic and $D_{1} / D_{5}$ receptor drugs on sEPSC frequency. Both nicotine $(1 \mu \mathrm{m} ; n=13)$ and SKF $81297(10 \mu \mathrm{m} ; n=23)$ increased the frequency of sEPSCs in DA neurons. SCH $23390(10 \mu \mathrm{m} ; n=12)$ and MLA (10 nм; $n=10)$, but not Dh $\beta E(1 \mu \mathrm{m} ; n=20)$ inhibited the effect of nicotine. SCH $23390(10 \mu \mathrm{m} ; n=10)$ also blocked the enhancement of sEPSC frequency by SKF 81297 . All data are normalized to baseline. ${ }^{*} p<0.05 ;{ }^{* *} p<0.01$. Calibration: $1 \mathrm{~s}, 25 \mathrm{pA}$.

tion phase of our exposure paradigm. As postsynaptic excitation can contribute to LTP induction, we assessed VTA DA neuron firing rate with extracellular recording during acute exposure to various pharmacological agents. Although both nicotine and
SKF 81297 increased the AMPAR/ NMDAR ratio, only nicotine treatment increased the firing rate of DA neurons (nicotine $=132 \pm 10 \%$ of baseline; prevalence $=17$ of 19 cells; $p<0.01$ ) (Fig. 4). $\operatorname{Dh} \beta E$ blocked the nicotine-induced increase of firing rate, as shown in Figure $4 B$ (nicotine $+\mathrm{Dh} \beta \mathrm{E}=103 \pm 9 \%$ of baseline; $n=5 ; p>0.05)$. However, neither MLA nor SCH23390 altered the nicotineinduced increase in VTA neuron firing, suggesting that depolarization by nicotine was mediated by $\beta 2$, but not $\alpha 7 \mathrm{nAChRs}$ (nicotine + MLA $=130 \pm 12 \%$ of baseline, prevalence $=7$ of 9 cells, $p<0.05$; nicotine + SCH $23390=144 \pm 15 \%$ of baseline, prevalence $=10$ of 10 cells, $p<$ $0.01)$. Moreover, although $D_{1} / D_{5}$ receptors are necessary for nicotine-induced synaptic plasticity, we did not see any contribution of these receptors to firing rate of VTA DA neurons, with or without nicotine.

Because nAChRs are expressed both somatodendritically on VTA DA neurons and presynaptically on glutamate and GABA inputs, we tested the contribution of indirect synaptic modulation to the excitatory effects of nicotine. When fast synaptic transmission via AMPA receptors and $\mathrm{GABA}_{\mathrm{A}}$ receptors was blocked by DNQX $(10 \mu \mathrm{M})$ and bicuculline $(20 \mu \mathrm{M})$, respectively, nicotine increased DA neuron firing rate with a similar magnitude as control (nicotine $=131 \pm 7 \%$ of control, prevalence $=20$ of 22 cells, $p<0.01$ ) (Fig. $4 D, E$ ). MLA had no effect on the nicotine-induced changes in excitability in the presence of synaptic blockers (nicotine + MLA $=119 \pm 4 \%$ of control, prevalence $=9$ of 10 cells, $p<0.05$ ). In contrast, $\mathrm{Dh} \beta \mathrm{E}$ completely inhibited the nicotine-induced increase in firing rate (nicotine $+\mathrm{Dh} \beta \mathrm{E}=100 \pm 6 \%$ of control, $n=5, p>0.05$ ), suggesting that nicotine excitation of DA neurons under these conditions is principally via direct activation of somatodendritic $\beta 2 \mathrm{nAChRs}$ on the DA neurons themselves. Interestingly, in the presence of synaptic blockers, both MLA and $\mathrm{Dh} \beta \mathrm{E}$ slightly reduced the baseline firing rate (Fig. $4 E$ ), with MLA reaching statistical significance $(90 \pm 5 \%$ of control, prevalence $=8$ of 10 cells, $p<$ 0.05). This suggests tonic cholinergic modulation of DA neuron firing rate in our slice preparation. Together, these data indicate that nicotine excitation of DA neurons is mediated predominantly by somatodendritic $\beta 2$-containing nAChRs, which likely contributes to the induction of synaptic plasticity. Moreover, the increased DA neuron activity may promote somatodendritic DA release to activate $D_{1} / D_{5}$ receptors to promote synaptic potentiation. 
Although we did not see evidence for a contribution of synaptic modulation to nicotine-induced excitation, synaptic modulation by nicotine can contribute to long-term plasticity (Mansvelder and McGehee, 2000; Mansvelder et al., 2002; Gao et al., 2010). These previous studies were conducted in tissue from young animals, and the presynaptic receptor subtypes could differ from the adult rats used in our current experiments. For this reason, and to assess dopaminergic modulation of synaptic activity, we tested the effects of acute activation of nicotinic and DA receptors on synaptic inputs to VTA DA neurons.

One measure of presynaptic function is paired-pulse ratio, which reflects neurotransmitter release probability. Both nicotine $(1 \mu \mathrm{M})$ and the $\mathrm{D}_{1} / \mathrm{D}_{5}$ agonist SKF $81297(10 \mu \mathrm{M})$ decreased paired-pulse ratio of the excitatory inputs to VTA DA neurons to 82 and $85 \%$ of baseline, respectively, suggesting an increase in release probability at the glutamatergic inputs to VTA DA neurons (baseline $=0.80 \pm 0.03$, nicotine $=0.66 \pm 0.03, n=18, p<$ 0.01 ; baseline $=0.80 \pm 0.03$, SKF $81297=0.68 \pm 0.03, n=11$, $p<0.01$ ) (Fig. 5).

To further investigate presynaptic modulation of excitatory transmission in this preparation, we tested the frequency of spontaneous excitatory synaptic currents (sEPSCs) and found that both nicotine and SKF 81297 increased sEPSC frequency. This effect is consistent with the findings from the paired-pulse stimulation experiments, suggesting a presynaptic enhancement of glutamate release by nicotinic and $D_{1} / D_{5}$ receptors (nicotine $=$ $169 \pm 25 \%$ of baseline, prevalence $=6$ of 13 cells, $p<0.05$; SKF $81297=145 \pm 10 \%$ of baseline, prevalence $=12 / 23$ cells, $p<$ 0.01 ) (Fig. 6). In addition, the nicotine effect is dependent on $\alpha 7$ but not $\beta 2 \mathrm{nAChRs}$, as MLA but not $\mathrm{Dh} \beta \mathrm{E}$ blocked the increase of sEPSC frequency (MLA + nicotine $=100 \pm 10 \%$ of baseline, $n=10, p>0.05 ; \operatorname{Dh} \beta E+$ nicotine $=149 \pm 12 \%$ of baseline, prevalence $=7$ of 20 cells, $p<0.01$ ) (Fig. $6 B$ ). These findings are similar to those reported previously in brain slices from young animals, although the magnitude of the effect is significantly greater in younger animals ( $400 \pm 98 \%$ of baseline) (Mansvelder and McGehee, 2000). Overall, the data show that nAChR subtypes expressed on presynaptic glutamate terminals are similar across development, but that the expression level or impact on synaptic strength diminishes with age.

Interestingly, the effects of nicotine on paired-pulse ratio and sEPSC frequency were blocked by the $D_{1} / D_{5}$ receptor antagonist SCH23390, suggesting a possible interaction between nicotinic and DA receptor systems [paired-pulse ratio: baseline $=0.70 \pm 0.05$; SCH $23390=0.76 \pm 0.07 ;$ SCh $23390+$ nicotine $=0.74 \pm 0.06 ; n=$ $12, p>0.05$ (Fig. $5 C, D$ ); sEPSC frequency: SCh23390 + nicotine $=$ $100 \pm 11 \%$ of baseline; $n=12, p>0.05$ (Fig. $6 A, B$ )]. The modulation of glutamatergic transmission by presynaptic $D_{1} / D_{5}$ receptors has been investigated in several brain areas, including the VTA, with inconsistent results. Some of these studies report enhanced glutamate release or transmission (Kalivas and Duffy, 1995; Schilström et al., 2006; Deng et al., 2009), while others show a decrease (Schilström et al., 2006). The discrepancies are likely due to differences in experimental conditions, animal age, and species. Our data support the idea that $\mathrm{D}_{1} / \mathrm{D}_{5}$ receptors enhance glutamate inputs to VTA DA neurons, and that $\alpha 7 \mathrm{nAChRs}$ overlap with $\mathrm{D}_{1} / \mathrm{D}_{5}$ receptors at presynaptic locations to modulate glutamate release.

The strong contribution of $\beta 2 \mathrm{nAChRs}$ to the excitatory effect of nicotine led us to hypothesize that the activation of these receptors by nicotine provides sufficient depolarization to induce synaptic potentiation. We tested this by introducing DNQX and bicuculline before nicotine in our in vitro exposure paradigm to block AMPA and $\mathrm{GABA}_{\mathrm{A}}$ activity, respectively. NMDA receptor

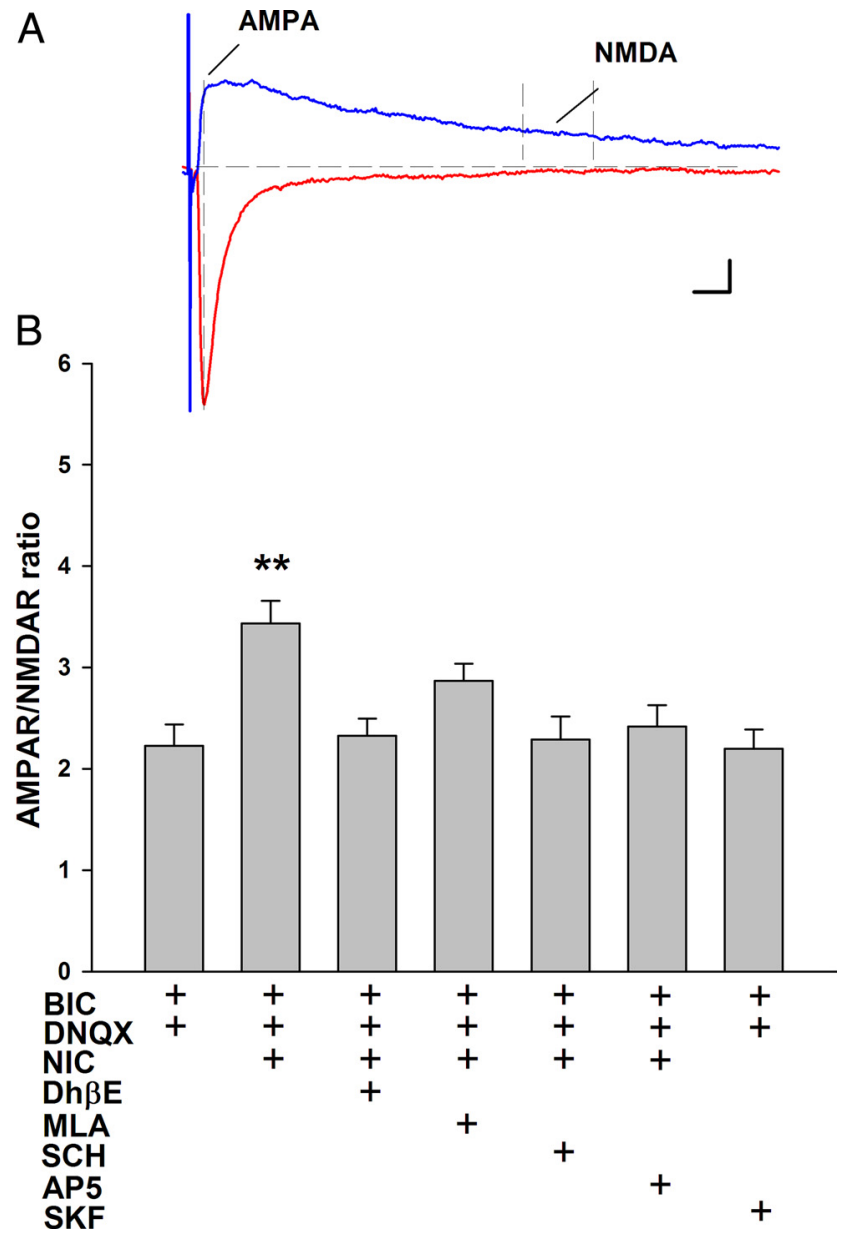

Figure 7. Nicotinic and $D_{1} / D_{5}$ receptor effects on AMPAR/NMDAR ratio in VTA DA neurons in the presence of fast synaptic blockers. The in vitro drug exposure paradigm shown in Figure 2 was modified to include antagonists to AMPA and GABA receptors DNQX (10 $\mu \mathrm{M})$ and bicuculline $(20 \mu \mathrm{M})$, respectively, $5 \mathrm{~min}$ before and during nicotine exposure. $A$, Representative EPSC recordings from a VTA DA neuron, illustrating the method for calculating AMPAR/NMDAR ratio. $B$, Summary of the effects on AMPAR/NMDAR ratio of treatment with various nicotinic and $D_{1} / D_{5}$ receptor drugs in the presence of DNQX and bicuculline. Compared with DNQX and bicuculline alone $(n=8)$, nicotine ( $1 \mu \mathrm{m} ; n=15)$ increased AMPAR/NMDAR ratio, and these effects were inhibited by $\operatorname{Dh} \beta \mathrm{E}(1 \mu \mathrm{m} ; n=7), \mathrm{MLA}(10 \mathrm{~nm} ; n=13), \operatorname{AP5}(50 \mu \mathrm{m} ; n=7)$, and SCH $23390(10 \mu \mathrm{m} ; n=11)$.SKF $81297(10 \mu \mathrm{m} ; n=13)$ had no effect on AMPAR/NMDAR ratio in the presence of DNQX and bicuculline. ANOVA, $p<0.0001$; Bonferroni post hoc test, ${ }^{* *} p<$ 0.01. Calibration: $5 \mathrm{~ms}, 30 \mathrm{pA}$.

function remained intact, as they are required for synaptic plasticity (Figs. 2, 3). Under these conditions, DNQX and bicuculline alone had no effect on the AMPAR/NMDAR ratio measured after the normal recovery period. However, nicotine did induce an increase of AMPAR/NMDAR ratio in the presence of the synaptic blockers to $155 \%$ of control (control $=2.2 \pm 0.2, n=8$; nicotine $=3.4 \pm 0.2, n=15$; ANOVA, $p<0.0001$; post hoc test, $p<$ $0.01)$ (Fig. 7). In contrast to the conditions without AMPAR and $\mathrm{GABA}_{\mathrm{A}}$ receptor blockade (Figs. 2, 3), both $\mathrm{Dh} \beta \mathrm{E}$ and MLA inhibited the nicotine-induced increase of AMPAR/NMDAR ratio, suggesting that both $\beta 2$ and $\alpha 7 \mathrm{nAChRs}$ contribute to plasticity when fast excitatory transmission is blocked $(\mathrm{Dh} \beta \mathrm{E}=2.3 \pm 0.2$, $n=7, p>0.05 ;$ MLA $=2.9 \pm 0.2, n=13, p>0.05$ ). These data also reveal a contribution of presynaptic $\alpha 7 \mathrm{nAChRs}$ to synaptic potentiation under conditions of suppressed synaptic input.

Similar to control recordings with synaptic transmission intact (Fig. 2), nicotine-induced plasticity was completely inhibited by pretreatment with AP5 or SCH23390 to 109.1 and $104.5 \%$ of control, 
A
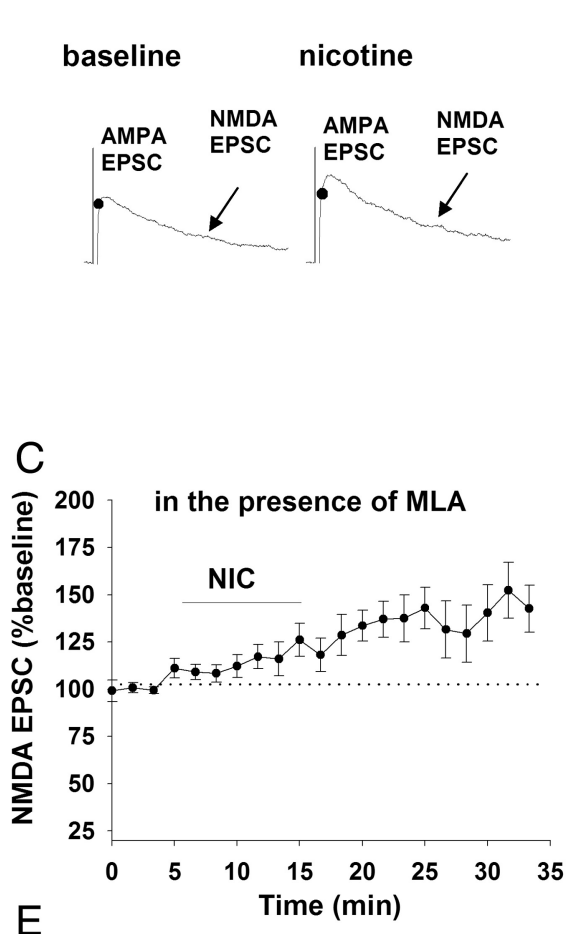

$\mathrm{D}$
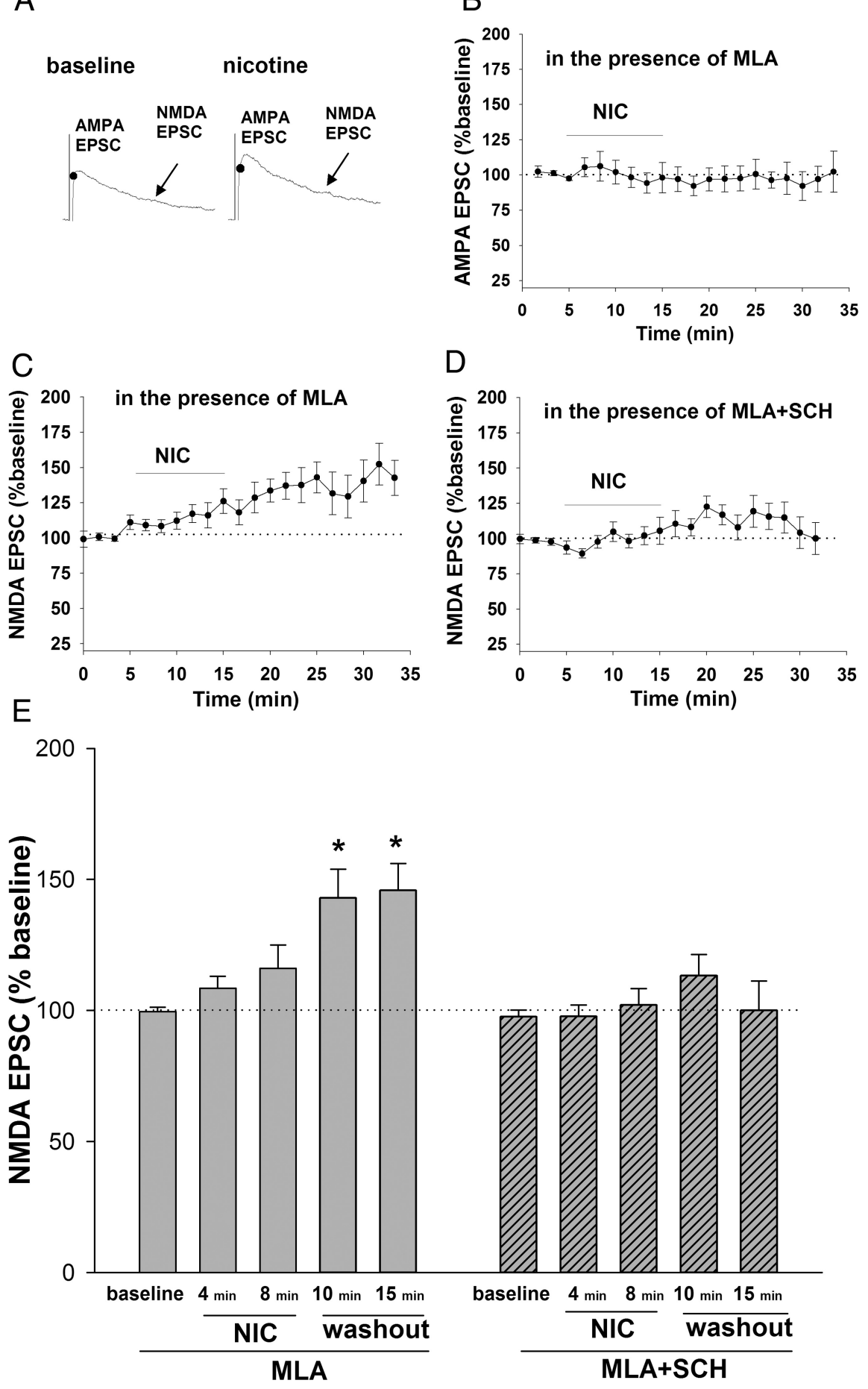

Figure 8. Nicotine enhances the NMDA EPSC in VTA DA neurons via $D_{1} / D_{5}$ receptor activation. $A$, Representative traces of EPSCs from an example neuron voltage-clamped at $+40 \mathrm{mV}$. AMPA EPSC peak was measured at the time corresponding to the peak EPSC at $-70 \mathrm{mV}$. NMDA EPSC was measured during a $10 \mathrm{~ms}$ window $40 \mathrm{~ms}$ after the peak of AMPA EPSC. $\boldsymbol{B}$, Time course of AMPA EPSC amplitudes before, during, and after a 10 min nicotine $(1 \mu \mathrm{m})$ exposure. MLA (10 $\mathrm{nm})$ was present throughout recording to inhibit presynaptic enhancement of release by nicotine ( $n=10$; data were averaged in $1.5 \mathrm{~min}$ bins). $C$, Time course of NMDA EPSC amplitudes before, during, and after a 10 min nicotine $(1 \mu \mathrm{m})$ exposure. MLA (10 nM) was present throughout recording ( $n=10$; data were averaged in $1.5 \mathrm{~min}$ bins). $\boldsymbol{D}$, Time course of NMDA EPSC amplitudes before, during, and after a 10 min nicotine $(1 \mu \mathrm{M})$ exposure, with both MLA (10 nM) and SCH $23390(10 \mu \mathrm{M})$ present throughout recording $(n=18$; data were averaged in 1.5 min bins). $\boldsymbol{E}$, Summary of the effect of nicotine on NMDA EPS(s in the presence of either MLA alone or MLA with SCH 23390 at selected time points during and after nicotine exposure. Nicotine induces a slow increase in NMDA EPSC, and this enhancement was maintained for at least $15 \mathrm{~min}$ after drug washout. $\mathrm{D}_{1} / \mathrm{D}_{5}$ receptor antagonist SCH23390 $(10 \mu \mathrm{m})$ inhibited the nicotine effect on NMDA EPSC. All data were normalized to baseline. ANOVA, $p=0.0002$; Bonferroni post hoc test, ${ }^{* *} p<0.01$. Calibration: $5 \mathrm{~ms}, 25 \mathrm{pA}$. respectively $(\mathrm{AP} 5=2.4 \pm 0.2, n=7, p>$ $0.05 ; \mathrm{SCH} 23390=2.3 \pm 0.2, n=11, p>$ 0.05 ) (Fig. 7). Interestingly, the $\mathrm{D}_{1} / \mathrm{D}_{5}$ agonist SKF 81297 alone no longer potentiated synaptic strength when AMPA and $\mathrm{GABA}_{\mathrm{A}}$ receptors were blocked, suggesting that intact excitatory transmission is necessary for $D_{1}-/ D_{5}$-mediated synaptic potentiation $($ SFK81297 $=2.2 \pm 0.2 ; n=13 ; p>$ 0.05) (Fig. 7). Thus, nicotine-induced synaptic potentiation requires $\beta 2$ nicotinic, $D_{1} /$ $\mathrm{D}_{5}$, and NMDA receptors, presumably all located on the postsynaptic DA neurons, whereas the presynaptic increase of glutamate mediated by $\alpha 7 \mathrm{nAChRs}$ can also contribute to the induction of synaptic plasticity under conditions of low excitatory drive, when the presynaptic effect synergizes with postsynaptic $\beta 2 \mathrm{nAChRs}$ to induce the observed changes.

As outlined above, $D_{1} / D_{5}$ receptors contribute to VTA synaptic plasticity and behavioral sensitization (Vezina, 1996; Argilli et al., 2008). Our data suggest that $\mathrm{D}_{1} / \mathrm{D}_{5}$ receptors enhance glutamate release in the VTA. However, presynaptic enhancement of glutamate release does not appear to be critical for plasticity when normal excitatory drive is intact, as selective $\alpha 7 \mathrm{nAChR}$ antagonist did not block synaptic potentiation. Therefore, a critical role of $D_{1} / D_{5}$ receptors in nicotine-induced synaptic plasticity might involve modulation of other steps in the induction of synaptic plasticity. Cocaine enhances NMDA receptor function via postsynaptic $D_{1} / D_{5}$ receptors in VTA DA neurons (Schilström et al., 2006). It is likely that nAChR-mediated direct excitation of DA neurons would increase somatodendritic DA release in the VTA to activate postsynaptic $D_{1} / D_{5}$ receptors, leading to enhanced NMDA receptor function. To test this possibility, we recorded evoked EPSCs at $+40 \mathrm{mV}$ to assess both AMPAR and NMDAR components in the VTA DA neurons (Fig. 8). All amplitudes were normalized to baseline, as determined by the average of the first three AMPA or NMDA EPSCs. We included MLA in the external solution to block the nicotine-induced increase of presynaptic glutamate release. Under this condition, we saw no change in the AMPA component of the EPSC after 10 min of 1 $\mu \mathrm{M}$ nicotine exposure, suggesting that nicotine did not increase presynaptic glutamate release under these conditions (Fig. 8 B). However, nicotine induced an increase in the NMDA EPSC during drug exposure that continued for at least 20 min (nicotine: $143 \pm 12 \%$ of baseline at 5 min after washout, $p<0.01 ; 146 \pm 11 \%$ 
of baseline at $15 \mathrm{~min}$ after washout, $p<$ 0.001) (Fig. 8C,E). When SCH23390 was added to the external solution to block $D_{1} / D_{5}$ receptors, nicotine no longer increased NMDA EPSCs (nicotine + SCH23390: $113 \pm 8 \%$ of baseline $5 \mathrm{~min}$ after washout; $100 \pm 12 \%$ of baseline 15 min after washout, $p>0.05$ ) (Fig. 8D,E). Because only NMDA EPSC, but not AMPA EPSC, was enhanced under this condition, a presynaptic effect of $D_{1} / D_{5}$ activation is an unlikely mediator. Instead, these results suggest that nicotine enhances NMDAR function via activation of somatodendritic $D_{1} / D_{5}$ receptors in VTA DA neurons.

The overlap in pharmacology of $\mathrm{D}_{1}$ and $\mathrm{D}_{5}$ receptors confounds the mechanistic interpretations somewhat, although the lack of $D_{1}$ mRNA expression in DA neurons suggests involvement of $\mathrm{D}_{5}$ receptors (Weiner et al., 1991; Yung et al., 1995). A role for $D_{5}$ receptors in cocaineinduced synaptic plasticity in VTA was suggested recently (Schilström et al., 2006; Argilli et al., 2008) and is supported by anatomical demonstration of $\mathrm{D}_{5}$ expression (Ciliax et al., 2000; Khan et al., 2000). Using a $\mathrm{D}_{5}$-specific antibody, we tested $\mathrm{D}_{5}$ receptor expression in VTA (Fig. 9). In this experiment, $82 \%$ of TH-positive cells ( 60 of 73 cells from 3 rats) were also $D_{5}$ positive, suggesting that a majority of the VTA DA neurons express $D_{5}$ receptors. Interestingly, we also observed that only $49 \%$ of the $\mathrm{D}_{5}$-positive cells (63 of 123 cells from 3 rats) are $\mathrm{TH}$ positive, which suggests the expression of $\mathrm{D}_{5}$ receptors on VTA GABA neurons. When the primary antibody was omitted from the staining procedure, we found no specific immunofluorescence in the VTA or other brain regions (Fig. 9B). These findings support the expression of $\mathrm{D}_{5}$ receptors in VTA DA neurons, which is consistent with the electrophysiology data showing that $D_{5}$ receptors contribute to synaptic plasticity of the excitatory inputs to VTA DA neurons.

\section{Discussion}

Our data demonstrate that in vitro nicotine exposure induces plasticity of the excitatory inputs to VTA DA neurons, similar to that seen following in vivo administration (Saal et al., 2003; Placzek et al., 2009; Gao et al., 2010). Direct activation of somatodendritic $\beta 2 \mathrm{nAChRs}$ increases the excitability of VTA DA neurons, which we expected to induce LTP directly. The AMPAR/NMDAR ratio change required a delay after drug exposure, suggesting a sequence of signaling events. DA neuron excitation apparently stimulates local DA release to activate $D_{5}$ receptors, which enhance NMDAR function, leading to nicotine-induced plasticity. Although cocaine and nicotine act on distinct primary targets, the effects converge with increased DA levels in VTA and the subsequent induction of LTP (Argilli et al., 2008).

Several nAChR subunit mRNAs are expressed by VTA neurons, including $\alpha 4, \alpha 5, \alpha 6, \alpha 7, \beta 2$, and $\beta 3$ (Klink et al., 2001), and electrophysiological studies demonstrate somatodendritic expression of $\alpha 4 \beta 2$ and $\alpha 7$ nAChRs (Pidoplichko et al., 1997; Klink et al., 2001; Pidoplichko et al., 2004; Yang et al., 2009). Mice that lack $\beta 2$ subunits do not show nicotine-induced increases in DA neuron firing, suggesting a key role for these receptors, predominantly $\alpha 4 \beta 2^{\star}$ nAChRs (Picciotto, 1998). In adult tissue slices, we found that $\alpha 7 \mathrm{nAChRs} \mathrm{have} \mathrm{minimal} \mathrm{effects}$ on DA neuron excitability. $\alpha 7 \mathrm{nAChRs}$ on presynaptic terminals can modulate glutamate release (Mansvelder and McGehee, 2000). There is also emerging evidence for important roles of $\alpha 6 \beta 2^{\star}$ nAChRs in VTA, where they influence nicotine selfadministration and DA release (Klink et al., 2001; Drenan et al., 2008; Pons et al., 2008; Gotti et al., 2010), but there are conflicting results on $\alpha 6$-mediated currents in VTA (Klink et al., 2001; Tapper et al., 2004; Yang et al., 2009). Here, we confirmed that adult rats express $n A C h R s$ similar to younger animals (i.e., DA neurons express predominantly $\beta 2^{*}$ nAChRs, and presynaptic $\alpha 7$ $n A C h R s$ modulate glutamate neurotransmission). The presynaptic nAChR effects are larger in young animals, suggesting a stronger role in plasticity (Mansvelder and McGehee, 2000; Placzek et al., 2009). We cannot exclude the possibility that nAChRs desensitize during the 15 min nicotine exposure. We previously reported that $\mathrm{nAChR}$ desensitization could decrease the inhibitory GABAergic drive to VTA DA neurons (Mansvelder et al., 2002). The lack of effect of nicotinic antagonists alone on DA neuron excitation or synaptic plasticity suggests that nAChR activation is required for LTP induction. The possibility that nAChR activation and desensitization work synergistically to alter excitability and plasticity in VTA awaits further testing.

Blockade of glutamate and GABA synaptic activity revealed tonic cholinergic modulation of DA neuron firing in our slice preparation, as $\mathrm{Dh} \beta \mathrm{E}$ or MLA depressed DA neuron firing rate. The cholinergic projections from brainstem synapse onto both DA and GABA neurons (Omelchenko and Sesack, 2005) and modulate DA neuron firing patterns in vivo (Lodge and Grace, 2006). In the presence of synaptic blockers, we found a stronger contribution of $\alpha 7$ than $\beta 2 \mathrm{nAChRs}$ to tonic firing rate.

\section{Somatodendritic $\beta 2 \mathrm{nAChRs}$ are critical for excitatory synaptic potentiation}

We previously reported that presynaptic $\alpha 7 \mathrm{nAChRs}$ contribute to LTP induction in DA neurons in brain slices from young rats (P10-P20) (Mansvelder and McGehee, 2000). We also found that desensitization of $\beta 2$-containing $n A C h R s$ on GABA neurons in VTA results in a persistent disinhibition of DA neurons (Mansvelder et al., 2002). In the current study, in vitro nicotine administration to slices from adult rats potentiated the excitatory 
inputs to VTA DA neurons via activation of somatodendritic $\beta 2$ nAChRs. Those receptors also mediated nicotine-induced excitation of VTA DA neurons, independent of presynaptic nAChR modulation of fast synaptic transmission. Spontaneous glutamate release coupled with excitation of DA neurons is apparently sufficient to induce synaptic plasticity. These data differ from recent findings that both $\alpha 7$ and $\beta 2 \mathrm{nAChRs}$ contribute to AMPAR/NMDAR ratio increase induced by in vivo nicotine administration (Gao et al., 2010). Differences in the nicotine exposure paradigm (in vivo vs in vitro) and animal age (16-23-d-old vs adult animals) may underlie the different observations. nAChR subunits show developmental regulation. In particular, $\alpha 7$ subunit mRNA peaks at postnatal day 21 in VTA DA neurons and declines into adulthood, whereas $\alpha 4$ and $\beta 2$ subunit levels in VTA are unchanged after birth (Azam et al., 2007). A decline in $\alpha 7 \mathrm{nAChR}$ expression may decrease the impact of these receptors on synaptic modulation in older animals. When we blocked fast synaptic transmission, a combination of presynaptic $\alpha 7$ and postsynaptic $\beta 2$ receptors was necessary for the induction of plasticity, suggesting that $\alpha 7 \mathrm{nAChRs}$ may contribute to plasticity under conditions of suppressed synaptic input.

Our findings agree with a large number of studies demonstrating that $\beta 2 \mathrm{nAChRs}$ mediate the long-term behavioral effects of nicotine. For example, maintenance of nicotine selfadministration requires $\beta 2$ subunit expression (Picciotto, 1998 ), and selectively re-expressing $\beta 2$ subunit into the VTA of $\beta 2-\mathrm{KO}$ mice restores nicotine self-administration behavior (Pons et al., 2008). Inhibition of $\alpha 4 \beta 2 \mathrm{nAChRs}$ interferes with locomotor sensitization and psychomotor stimulant-induced DA release in NAc (Schoffelmeer et al., 2002). Tapper et al. (2004) reported that mice genetically engineered to express hypersensitive $\alpha 4 \mathrm{nAChRs}$ showed place-preference and locomotor sensitization in response to low nicotine concentrations that are inactive at other nAChRs.

The pursuit of mechanisms underlying the persistent behavioral changes by drugs of abuse has focused upon the induction of LTP. For example, self-administration but not passive delivery of nicotine elevates VTA DA neuron activity via LTP of excitatory inputs from bed nucleus of the stria terminalis (Caillé et al., 2009). Our finding that somatodendritic $\beta 2$ nAChRs in VTA DA neurons are necessary for nicotine-induced synaptic plasticity provides additional mechanistic insight into $\mathrm{nAChR}$-dependent behaviors.

\section{Role of $D_{1} / D_{5}$ receptors in nicotine-induced synaptic potentiation}

$D_{1} / D_{5}$ receptors contribute to the behavioral effects of psychomotor stimulants. Intra-VTA administration of $\mathrm{D}_{1} / \mathrm{D}_{5}$ agonists can induce locomotor sensitization in animals, whereas $\mathrm{D}_{1} / \mathrm{D}_{5}$ inhibition in VTA blocks amphetamine-induced locomotor sensitization and enhanced DA release in NAc (Vezina, 1996). In addition, inhibiting $D_{1} / D_{5}$ receptors in the VTA reduces intraVTA self-administration of cocaine in rats (Ranaldi and Wise, 2001 ), and systemic inhibition of $D_{1} / D_{5}$ receptors abolishes selfadministration of nicotine (David et al., 2006). $D_{1} / D_{5}$ agonist administration increases extracellular glutamate in VTA in microdialysis experiments (Kalivas and Duffy, 1995), and it increases sEPSC frequency in dissociated VTA DA neurons (Deng et al., 2009). However, others report $D_{1}-/ D_{5}$-mediated suppression of glutamate release in VTA (Schilström et al., 2006). The discrepancy is likely due to differences in experimental design, animal age, and species. Here, we found that $\mathrm{D}_{1} / \mathrm{D}_{5}$ receptors enhance glutamate transmission in VTA, and that $\mathrm{D}_{1} / \mathrm{D}_{5}$ recep- tors are also necessary for presynaptic $\alpha 7 \mathrm{nAChR}$ increases in glutamate release. The nature of this receptor interaction is unknown.

A key role for $D_{1} / D_{5}$ receptors in synaptic potentiation appears to reside within the DA neurons. Nicotine increased postsynaptic NMDA receptor function for at least 20 min after drug washout, without affecting AMPA EPSC amplitude, suggesting that the $D_{1} / D_{5}$ receptors are expressed somatodendritically on the DA neurons. Currently available drugs do not distinguish between $D_{1}$ and $D_{5}$ receptors. Schilström et al. (2006) reported a similar cocaine-induced enhancement of NMDAR function in VTA DA neurons that was dependent on the somatodendritic $\mathrm{D}_{5}$ receptors. Previous studies, along with our immunohistochemistry data, support $\mathrm{D}_{5}$ expression by VTA DA neurons (Ciliax et al., 2000; Khan et al., 2000), whereas neither $D_{1}$ receptor protein nor mRNA has been reported in VTA (Weiner et al., 1991; Yung et al., 1995). Nicotine excitation of DA neurons likely increases somatodendritic DA release to activate local $\mathrm{D}_{5}$ receptors, leading to increased NMDAR expression. Potentiation of NMDAR function appears to be critical for induction of synaptic plasticity, as inhibition of either $D_{1} / D_{5}$ or NMDA receptors abolished the nicotine-induced increase of AMPAR/NMDAR ratio in DA neurons. In addition, enhanced NMDAR function could facilitate LTP induction even after somatodendritic $\beta 2 \mathrm{nAChRs}$ are desensitized.

In conclusion, our data show that in vitro exposure of nicotine to brain slices from drug-naive adult rats induces excitatory synaptic plasticity. We propose a mechanism of synaptic potentiation initiated by nicotine-induced depolarization of DA neurons via activation of somatodendritic $\alpha 4 \beta 2^{\star}$ nAChRs. This stimulates DA release in VTA and activation of $\mathrm{D}_{5}$ receptors that enhance NMDAR function. Ongoing glutamatergic activity in the slice eventually leads to changes in the synaptic levels of AMPA receptors in DA neurons. In our tissue slices from adult rats, synaptic modulation by presynaptic nAChRs can contribute to plasticity, but only under conditions of suppressed synaptic activity and in combination with somatodendritic $\beta 2$-containing nAChRs. Our findings, along with recent investigations into the effects of cocaine (Schilstrom et al., 2006; Argilli et al., 2008) highlight remarkable mechanistic overlap between the effects of nicotine and cocaine within this circuitry. Understanding the common receptors and signaling pathways may help identify more effective treatments for psychostimulant addiction.

\section{References}

Argilli E, Sibley DR, Malenka RC, England PM, Bonci A (2008) Mechanism and time course of cocaine-induced long-term potentiation in the ventral tegmental area. J Neurosci 28:9092-9100.

Azam L, Chen Y, Leslie FM (2007) Developmental regulation of nicotinic acetylcholine receptors within midbrain dopamine neurons. Neuroscience 144:1347-1360.

Borgland SL, Malenka RC, Bonci A (2004) Acute and chronic cocaineinduced potentiation of synaptic strength in the ventral tegmental area: electrophysiological and behavioral correlates in individual rats. J Neurosci 24:7482-7490.

Caillé S, Guillem K, Cador M, Manzoni O, Georges F (2009) Voluntary nicotine consumption triggers in vivo potentiation of cortical excitatory drives to midbrain dopaminergic neurons. J Neurosci 29:10410-10415.

Centers for Disease Control and Prevention (2004) The health consequences of smoking: a report of the Surgeon General. Atlanta: U.S. Department of Health and Human Services.

Ciliax BJ, Nash N, Heilman C, Sunahara R, Hartney A, Tiberi M, Rye DB, Caron MG, Niznik HB, Levey AI (2000) Dopamine (D5) receptor immunolocalization in rat and monkey brain. Synapse 37:125-145.

David V, Besson M, Changeux JP, Granon S, Cazala P (2006) Reinforcing effects of nicotine microinjections into the ventral tegmental area of mice: 
Dependence on cholinergic nicotinic and dopaminergic D1 receptors. Neuropharmacology 50:1030-1040.

Demuro A, Palma E, Eusebi F, Miledi R (2001) Inhibition of nicotinic acetylcholine receptors by bicuculline. Neuropharmacology 41:854-861.

Deng C, Li KY, Zhou C, Ye JH (2009) Ethanol enhances glutamate transmission by retrograde dopamine signaling in a postsynaptic neuron/synaptic bouton preparation from the ventral tegmental area. Neuropsychopharmacology 34:1233-1244.

Drenan RM, Grady SR, Whiteaker P, McClure-Begley T, McKinney S, Miwa JM, Bupp S, Heintz N, McIntosh JM, Bencherif M, Marks MJ, Lester HA (2008) In vivo activation of midbrain dopamine neurons via sensitized, high-affinity alpha6 nicotinic acetylcholine receptors. Neuron 60:123-136.

Ford CP, Mark GP, Williams JT (2006) Properties and opioid inhibition of mesolimbic dopamine neurons vary according to target location. J Neurosci 26:2788-2797.

Gao M, Jin Y, Yang K, Zhang D, Lukas RJ, Wu J (2010) Mechanisms involved in systemic nicotine-induced glutamatergic synaptic plasticity on dopamine neurons in the ventral tegmental area. J Neurosci 30:13814-13825.

Gotti C, Guiducci S, Tedesco V, Corbioli S, Zanetti L, Moretti M, Zanardi A, Rimondini R, Mugnaini M, Clementi F, Chiamulera C, Zoli M (2010) Nicotinic Acetylcholine receptors in the mesolimbic pathway: primary role of ventral tegmental area $\alpha 6 \beta 2^{\star}$ receptors in mediating systemic nicotine effects on dopamine release, locomotion, and reinforcement. J Neurosci 30:5311-5325.

Johnson SW, North RA (1992) Two types of neurone in the rat ventral tegmental area and their synaptic inputs. J Physiol 450:455-468.

Kalivas PW, Alesdatter JE (1993) Involvement of N-methyl-D-aspartate receptor stimulation in the ventral tegmental area and amygdala in behavioral sensitization to cocaine. J Pharmacol Exp Ther 267:486-495.

Kalivas PW, Duffy P (1995) $D_{1}$ receptors modulate glutamate transmission in the ventral tegmental area. J Neurosci 15:5379-5388.

Kauer JA, Malenka RC (2007) Synaptic plasticity and addiction. Nat Rev Neurosci 8:844-858.

Khan ZU, Gutiérrez A, Martín R, Peñafiel A, Rivera A, de la Calle A (2000) Dopamine D5 receptors of rat and human brain. Neuroscience 100:689-699.

Klink R, de Kerchove d'Exaerde A, Zoli M, Changeux JP (2001) Molecular and physiological diversity of nicotinic acetylcholine receptors in the midbrain dopaminergic nuclei. J Neurosci 21:1452-1463.

Lodge DJ, Grace AA (2006) The laterodorsal tegmentum is essential for burst firing of ventral tegmental area dopamine neurons. Proc Natl Acad Sci U S A 103:5167-5172.

Mansvelder HD, McGehee DS (2000) Long-term potentiation of excitatory inputs to brain reward areas by nicotine. Neuron 27:349-357.

Mansvelder HD, Keath JR, McGehee DS (2002) Synaptic mechanisms underlie nicotine-induced excitability of brain reward areas. Neuron 33:905-919.

Margolis EB, Lock HJ, Hielmstad GO, Fields HL (2006) The ventral tegmental area revisited: is there an electrophysiological marker for dopaminergic neurons? J Physiol 577:907-924.

Omelchenko N, Sesack SR (2005) Laterodorsal tegmental projections to identified cell populations in the rat ventral tegmental area. J Comp Neurol 483:217-235.

Picciotto MR, Zoli M, Rimondini R, Léna C, Marubio LM, Pich EM, Fuxe K, Changeux JP (1998) Acetylcholine receptors containing the beta2 subunit are involved in the reinforcing properties of nicotine. Nature 391:173-177.
Pidoplichko VI, DeBiasi M, Williams JT, Dani JA (1997) Nicotine activates and desensitizes midbrain dopamine neurons. Nature 390:401-404.

Pidoplichko VI, Noguchi J, Areola OO, Liang Y, Peterson J, Zhang T, Dani JA (2004) Nicotinic cholinergic synaptic mechanisms in the ventral tegmental area contribute to nicotine addiction. Learn Mem 11:60-69.

Placzek AN, Zhang TA, Dani JA (2009) Age dependent nicotinic influences over dopamine neuron synaptic plasticity. Biochem Pharmacol 78:686-692.

Pons S, Fattore L, Cossu G, Tolu S, Porcu E, McIntosh JM, Changeux JP, Maskos U, Fratta W (2008) Crucial role of $\alpha 4$ and $\alpha 6$ nicotinic acetylcholine receptor subunits from ventral tegmental area in systemic nicotine self-administration. J Neurosci 28:12318-12327.

Ranaldi R, Wise RA (2001) Blockade of $\mathrm{D}_{1}$ dopamine receptors in the ventral tegmental area decreases cocaine reward: possible role for dendritically released dopamine. J Neurosci 21:5841-5846.

Rose JE, Mukhin AG, Lokitz SJ, Turkington TG, Herskovic J, Behm FM, Garg S, Garg PK (2010) Kinetics of brain nicotine accumulation in dependent and nondependent smokers assessed with PET and cigarettes containing ${ }^{11}$ C-nicotine. Proc Natl Acad Sci U S A 107:5190-5195.

Saal D, Dong Y, Bonci A, Malenka RC (2003) Drugs of abuse and stress trigger a common synaptic adaptation in dopamine neurons. Neuron 37:577-582.

Schilström B, Yaka R, Argilli E, Suvarna N, Schumann J, Chen BT, Carman M, Singh V, Mailliard WS, Ron D, Bonci A (2006) Cocaine enhances NMDA receptor-mediated currents in ventral tegmental area cells via dopamine $\mathrm{D}_{5}$ receptor-dependent redistribution of NMDA receptors. J Neurosci 26:8549-8558.

Schoffelmeer AN, De Vries TJ, Wardeh G, van de Ven HW, Vanderschuren LJ (2002) Psychostimulant-induced behavioral sensitization depends on nicotinic receptor activation. J Neurosci 22:3269-3276.

Tapper AR, McKinney SL, Nashmi R, Schwarz J, Deshpande P, Labarca C, Whiteaker P, Marks MJ, Collins AC, Lester HA (2004) Nicotine activation of alpha $4^{\star}$ receptors: sufficient for reward, tolerance, and sensitization. Science 306:1029-1032.

Ungless MA, Whistler JL, Malenka RC, Bonci A (2001) Single cocaine exposure in vivo induces long-term potentiation in dopamine neurons. Nature 411:583-587.

Vezina $\mathrm{P}$ (1996) $\mathrm{D}_{1}$ dopamine receptor activation is necessary for the induction of sensitization by amphetamine in the ventral tegmental area. J Neurosci 16:2411-2420.

Weiner DM, Levey AI, Sunahara RK, Niznik HB, O’Dowd BF, Seeman P, Brann MR (1991) D1 and D2 dopamine receptor mRNA in rat brain. Proc Natl Acad Sci U S A 88:1859-1863.

Wolf ME, Sun X, Mangiavacchi S, Chao SZ (2004) Psychomotor stimulants and neuronal plasticity. Neuropharmacology 47:61-79.

Yang K, Hu J, Lucero L, Liu Q, Zheng C, Zhen X, Jin G, Lukas RJ, Wu J (2009) Distinctive nicotinic acetylcholine receptor functional phenotypes of rat ventral tegmental area dopaminergic neurons. J Physiol 587:345-361.

Yung KK, Bolam JP, Smith AD, Hersch SM, Ciliax BJ, Levey AI (1995) Immunocytochemical localization of D1 and D2 dopamine receptors in the basal ganglia of the rat: light and electron microscopy. Neuroscience 65:709-730.

Zhang TA, Placzek AN, Dani JA (2010) In vitro identification and electrophysiological characterization of dopamine neurons in the ventral tegmental area. Neuropharmacology 59:431-436. 